\title{
Cyclic behavior of thin RC Peruvian shear walls: full-scale experimental investigation and numerical simulation
}

\author{
Luis G. QUIROZ ${ }^{\dot{\gamma}, a}$, Yoshihisa MARUYAMA ${ }^{\dagger}$ and Carlos ZAVALA ${ }^{*}$ \\ ${ }^{\dagger}$ Department of Urban Environment Systems, Chiba University, 1-33 Yayoi-cho, Inage-ku, \\ Chiba 263-8522, Japan \\ $\$$ Japan-Peru Center for Earthquake Engineering Research and Disaster Mitigation, \\ National University of Engineering, Tupac Amaru Avenue 1150, Lima 25, Peru
}

\begin{abstract}
The experimental results of seven full-scale thin RC shear walls subjected to cycling loading are presented. The objective of these experiments is to evaluate the use of electro-welded wire mesh as the main reinforcement instead of a conventional reinforcement. Six walls are equipped with the electro-welded wire mesh, which is made of a non-ductile material, and one wall is reinforced with conventional bars, which are made of a ductile material. A single layer of main reinforcement is used in both directions. The edges of all walls are reinforced with conventional bars. These walls are widely used in low- and mid-rise buildings in central Peru, especially in Lima City. The structural behaviors are examined in terms of strength, stiffness, dissipated energy, and equivalent viscous damping. Finally, the "Three-parameter Park hysteretic model" is calibrated in order to reproduce the behaviors of the thin walls reinforced with the conventional reinforcement and electro welded-wire mesh. The parameters are applied to the results of the other walls reinforced by the electro-welded wire mesh. The results of numerical simulations are in good agreement with experimental results.
\end{abstract}

Keywords: RC shear wall, cyclic loading, full-scale test, Park hysteretic model.

\footnotetext{
${ }^{a}$ Correspondence to: Luis G. QUIROZ, Department of Urban Environment Systems, Chiba University, 1-33 Yayoi-cho, Inage-ku, Chiba 263-8522, Japan Tel: +81-43-292-3555, Fax: +81-43-292-3558

E-mail:1gquiroz@uni.edu.pe
} 


\section{INTRODUCTION}

Shear walls are an important aspect of buildings. They brace structures against lateral forces such as those generated by wind or earthquakes. The shear wall will experience inelastic deformations usually at the base of the wall during a strong earthquake. These inelastic deformations are beneficial to structures from an economic point of view. If we want to keep the structures with only elastic deformations at the occurrence of an earthquake, the cost would be increased.

During the last big earthquake in Latin America, the 2010 Chile earthquake, some buildings whose resistance systems to lateral loads were thin walls suffered from severe damage and in some cases collapsed [1]. In Peru, especially in Lima City, many similar types of buildings have been built since 2000, and the number of these types of buildings being constructed has been increasing over the years. However, Lima City has not been hit by a big earthquake since 1974. Therefore, it is difficult to know the behaviors of these buildings during seismic events.

In 1998, a group of engineers in Peru initiated a monotonic and cyclical testing program for thin walls with nominal strength to a compression of $9.81 \mathrm{MPa}\left(100 \mathrm{kgf} / \mathrm{cm}^{2}\right)$ for structural concrete. At that time, these thin walls were used in one- or two-story buildings, with vertical and horizontal reinforcements below the minimum specified in the Peruvian design code for structural walls [2].

In 1999, the first apartment building with more than three stories was designed and constructed in the Miraflores district, Lima, Peru. Materials Bank (BANMAT) promoted this project in order to relieve the slumming of land. From 2001 to 2005, other companies supported new investigations on this system. Those investigations were developed by both the Japan-Peru Center for Earthquake Engineering Research and Disaster Mitigation (CISMID) of the National University of Engineering (UNI) and the Pontifical Catholic University of Peru (PUCP). These investigations were directed at evaluating the impact in the capacity curves of the differences in stress-strain curves of ductile bars and an electro-welded wire mesh. They also evaluated the implications of the absence of confinement at the edges of the walls owing to their small thicknesses. With the results of these studies, some changes were made on standards E.030 [3] and E.060 [4] that incorporated specific articles on these types of walls called "limited ductility walls." Both CISMID and PUCP subsequently continued the research to evaluate the use of electro-welded wire mesh as reinforcement of these walls. 
A way to understand the behavior of an element or entire structure is through experimentation. In 1995, Pilakoutas and Elnashai studied the cyclic behavior of reinforced concrete cantilever walls [5] and compared the experimental results with analytical solutions with respect to stiffness characteristics, limit states, and deformational characteristics [6]. Tasnimi [7] analyzed the experimental results of four structural shear walls of conventional constructions subjected to cyclic lateral displacement. The results were analyzed in terms of cracking, strength degradation, deformation, stiffness, and ductility. Riva et al. [8] analyzed the results of an experimental test on a full-scale RC structural wall subjected to cyclic loading. In the studies previously mentioned, the arrangement of the main reinforcement was horizontal and vertical. Shaingchin et al. [9] studied the influence of web diagonal reinforcement on the cyclic behavior of structural walls. Most of these studies refer to the use of conventional bars as the main reinforcement and changing the amount or arrangement, but information on the use of electro-welded wire mesh in structural walls is limited. Tang and Zhang [10] developed a numerical model of a generic RC shear wall and foundation considering the nonlinear behaviors of the shear wall and the foundation response. Gonzales and López-Almansa [11] evaluated seismic performance of seven existing representative thin shear-wall and mid-height buildings located in Peru performing static and dynamic nonlinear response analyses.

In the present paper, the results of experiments carried out at CISMID in 2004 [12] will be investigated in detail by numerical simulation. Based on the experimental results, the "Three-parameter Park hysteretic model" is calibrated and validation of the numerical simulation is discussed. The walls employed in this study are the typical type of walls used in Peruvian buildings.

\section{DESCRIPTION OF THE FULL-SCALE EXPERIMENT}

In 2004, a series of experiments were carried out on the thin walls with identical dimensions but with different amounts and types of reinforcement. The walls were cast at full scale with constant thickness and their height-to-length $\left(\mathrm{h}_{\mathrm{w}} / 1_{\mathrm{w}}\right)$ ratio was set to 0.91 . These walls were subjected to slow cyclic horizontal loading. The responses of seven walls were studied in terms of elastic stiffness and maximum strength [12].

\subsection{Details of specimens}

Two types of reinforcements were used in the experiment: a conventional 
reinforcement, which is made of a ductile material, and an electro-welded wire mesh, which is made of a non-ductile material. A comparison of tensile tests carried out in bars of different types of reinforcement has been conducted in a previous study [2]. In this earlier study, it was observed that Peruvian conventional reinforcement bars have a yield zone, whereas the electro-welded wire mesh does not show such characteristics.

The tensile tests in conventional reinforcement bars under the denomination A615-G60 were carried out at laboratories of the National University of Engineering and Pontifical Catholic University. The bars yielded under a tensile stress of approximately 450 $\mathrm{MPa}$ with an associated strain of 0.002 . In the case of electro-welded wire mesh, the yield strain was 0.0035 , and the yield stress was approximately $485 \mathrm{MPa}$ (Fig. 1). Although the modulus of elasticity for the electro-welded wire mesh is lower than that for the conventional rebar, these values coincide with those presented by the technical manual provided by the producer [13]. The compression strength of concrete used in the walls was 17.16 $\mathrm{MPa}$ according to the tests carried out on cylindrical specimens. The nominal dimensions of all specimens were a height of $2400 \mathrm{~mm}$, a length of $2650 \mathrm{~mm}$, and a thickness of $100 \mathrm{~mm}$. A distribution slab $2000 \mathrm{~mm}$ wide and $120 \mathrm{~mm}$ thick was built in the top of the walls. These walls were monolithically connected to a foundation, which was used to fix the wall to the floor in order to consider a fully fixed footing. The nominal dimensions of this foundation were a width of $900 \mathrm{~mm}$ and a height of $300 \mathrm{~mm}$.

The variations of reinforcement in walls are presented in Table 1 . The walls can be classified into three groups according to the type of main reinforcement: MQE188EP (Group A), MQE257EP (Group B), and MFIEN3EP (Group C). The first group is formed by three walls equipped with the same main reinforcement (mesh QE188). The first two walls of this group had dowels identical to those of the main reinforcement, and one had dowels with the conventional reinforcement bars with a diameter of $9.5 \mathrm{~mm}$, spaced every 250 mm (\#3@250). The second group of walls had main reinforcement mesh, QE257, with a variation in the dowels similar to Group A. The last group consisted of a wall with the main reinforcement and dowels of \#3@ 250. All of the walls had the same

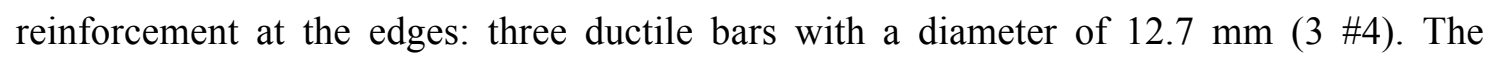
meshes used in specimens had the characteristics presented in Table 2.

Figure 2 shows the geometry and distribution of reinforcement in MQE188EP and MFIEN3EP. The distribution of reinforcement of MQE257EP is similar to the MQE188EP. 


\subsection{Instrumentation and load frame}

The instrumentation of the specimens with force transducers and displacement transducers (LVDTs) allowed the monitoring of loads and in-plane displacements. To support these devices, a steel frame was built around each specimen. This steel frame was also used as a reaction frame for a vertical actuator that applied a confinement load to the walls. A reaction wall was used as a support for a lateral electro-hydraulic actuator of \pm 490 $\mathrm{kN}$ with the capacity to produce displacements of $\pm 200 \mathrm{~mm}$. This actuator was controlled with a Shimadzu 9525 controller and a personal computer with an analog-to-digital and digital-to-analog signal conversion card. The behaviors of walls were monitored through the sensors connected to a signal conditioner that transfers the data to a computer for every measurement step. The working range of LVDTs varies from 10 to $100 \mathrm{~mm}$. Figure 3(a) shows the positions of LVDTs on walls, and Figure 3(b) shows the load application scheme.

\subsection{Loading history and testing procedure}

Before applying the lateral load, a vertical load of approximately $186 \mathrm{kN}$, which represents $4 \%$ of the maximum capacity of wall to compression, was applied through an electro-hydraulic actuator. This load represents the weight that should be expected at the bottom of a central wall in a building with five stories and was kept constant throughout the tests.

In order to simulate the loading expected during an earthquake, a simple horizontal cyclic loading history with small increments was used. The horizontal loading was applied at a quasi-static rate with cycles controlled by displacement. The location of this horizontal load was the center of the distribution slab.

Table 3 shows the numbers of phases and cycles imposed on the walls and also their respective target displacement at the top. When the target displacement is generated, the force was kept constant to assess the distribution and widths of cracks. Then, the specimens were gradually unloaded. Three cycles per phase were applied. In the case of MFIEN3EP, the first two phases kept the wall within the elastic range if we compare the displacements at the top with the theoretical yield displacement. The same thing can be said for the other walls.

\section{TEST RESULTS}




\subsection{Load-displacement diagrams}

The relationships between the applied load and displacement at the top of the wall are shown in Figure 4. The displacement was recorded by LVDT-5 shown in Figure 3(a).

Although the walls of Group A, MQE188EP-01 and MQE188EP-02, have the same dimensions and reinforcement, their hysteretic curves are slightly different. The hysteretic curve observed for the wall MQE188EP-02 exhibits more pinching and unloading stiffness degradation than that for the wall MQE188EP-01. In the case of Group B, MQE257EP-01 and MQE257EP-02 show similar hysteretic curves. The hysteretic curve obtained from MQE257EP-03 (Figure 4(f)) shows an asymmetrical shape in the 12th cycle. The hysteretic curve of MFIEN3EP (Figure 4(g)) shows a reduction in strength in phase 3 and then an increment in strength in the subsequent phases. This tendency is neither observed in the negative part of the curve nor in other walls. To calibrate the parameters of the numerical model, the experimental results in the negative part of the hysteretic curve for the wall MFIENE3P and those of the hysteretic curve for the wall MQE257EP-01 were mainly used in this study.

\subsection{Crack pattern and failure mode}

Table 4 describes the behavior of the walls in every phase during the tests qualitatively. In summary, most of the walls presented a horizontal crack along their base (joint between the wall and foundation) in phase 1. The cause of these initial cracks could be the time gap between the construction of the foundation and walls. Cracks due to flexure appear between phases 2 and 3, and their lengths increase between phases 3 and 4. Also, in this period, shear cracks appeared. The crushing in the corners and slippage of the base began between phases 5 and 6 . Figure 5 shows the final states of some walls.

\section{EVALUATION OF STRUCTURAL CHARACTERISTICS OF THE THIN WALLS BASED ON EXPERIMENTS TO CALIBRATE THE NUMERICAL MODEL}

\subsection{Maximum strength of the walls}

The maximum strengths are estimated from the experiments as the peak lateral loads from the hysteretic curves. A summary of these results is shown in Table 5. Figure 6(a) shows the skeleton curves estimated from the experimental results for all walls. The behaviors of the walls in the elastic range are similar, but they show slightly different responses in the inelastic range. The walls reinforced with the mesh QE188 exhibit the 
lowest maximum strength, and the walls reinforced with the conventional reinforcement exhibit the highest maximum strength. As for MFIEN3EP, the strength slightly increases even after a displacement of $12 \mathrm{~mm}$.

\subsection{Initial stiffness and stiffness degradation}

To estimate the initial stiffness before cracking, the expressions presented below were used, which consider the case of a cantilever beam. In this equation, shear and flexural deformations are considered.

$$
K=\frac{1}{\left(\frac{h_{w}{ }^{3}}{3 E I}+\frac{h_{w}}{G A v}\right)}
$$

where $\mathrm{E}$ is the elastic modulus and $\mathrm{G}$ is the shear modulus. They are set as $19.45 \mathrm{GPa}$ and $7.75 \mathrm{GPa}$, respectively. Av is the shear area, and I is the moment of inertia. Because all the walls have the same geometry and equivalent elasticity modulus, the initial stiffness for all specimens is $342.02 \mathrm{kN} / \mathrm{mm}$.

The initial positive stiffness $\left(\mathrm{K}_{\mathrm{ini}}{ }^{+}\right)$is defined by taking an average value of the three cycles in the first phase as the ratio between the force and the maximum positive horizontal displacement. The initial negative stiffness $\left(\mathrm{K}_{\text {ini }}{ }^{-}\right)$is defined for the negative part of a cycle in the similar manner (Figure 6(b)). The initial equivalent stiffness $\left(\mathrm{K}_{\text {ini-eq }}\right)$ is estimated as the slope between the peak positive and negative displacements for the first cycle in the first phase. Table 5 presents the initial stiffness obtained from the experimental results for the first phase.

As seen from the data in Table 5, there is a discrepancy between the theoretical value $\left(\mathrm{K}_{\text {Theo }}\right)$ and those from the experimental results. The same table shows a comparison between the maximum moment developed during the first phase and the theoretical moment for flexural cracking $\left(\mathrm{M}_{\mathrm{CR}}\right)$. As observed, the latter moment is not exceeded for the walls MQE188EP-01, MQE188EP-02, MQE188EP-03, MQE257EP-01, and MFIEN3EP. Based on these values, the reduction in initial stiffness could not be explained with respect to the moment for flexural cracking. Cracking of concrete owing to drying shrinkage before the test could result in these differences $[14,15]$. The initial stiffness estimated from the test is almost $55 \%$ of the theoretical value. A similar tendency has been reported previously [16].

Table 6 shows the variation in the initial stiffness for MFIEN3EP. Owing to the development of cracks, the equivalent initial stiffness decreases as the displacement 
increases, as expected. Similar tendencies could be observed for the other walls.

Figure 6(b) shows the variation in the lateral equivalent stiffness $\left(\mathrm{K}_{\mathrm{eq}}\right)$ with respect to the total displacement at the top of the wall. Specimen MQE188EP-01 exhibits more reduction in lateral equivalent stiffness than the other walls although it has the same tendency. In the later test cycles, MFIEN3EP exhibits larger lateral equivalent stiffness than the other walls. The lateral stiffness of all the walls implies a considerable reduction in the inelastic range. The values reduced to almost $46 \%$ of the initial values when the walls reached the yielding state $\left(\Delta_{\text {TOP }}=3 \mathrm{~mm}\right)$. On the other hand, when the walls reached the displacement limit established by the Peruvian code [3], the lateral stiffness reduced to almost $16 \%$ of the initial value $\left(\Delta_{\mathrm{TOP}}=12 \mathrm{~mm}\right)$. This could be produced by an increase in the width and depth of cracks.

\subsection{Dissipated energy and equivalent viscous damping}

One of the requirements in the performance-based design is to control damage during an earthquake. Damage can be expressed as a linear combination of the maximum deformation ratio and the energy dissipation during cyclic loading. In order to control damage, structures must be able to dissipate energy reliably during cyclic loads $[17,18]$.

A convenient approach to estimate the energy dissipated is to determine the area under the load-displacement diagrams [6, 19]. Figures 6(c) and 6(d) show the energy dissipated and cumulative dissipated energy as a function of the displacement at the top respectively.

As can be seen in the previous figures, all specimens exhibit almost the same amount of dissipated energy in every cycle except for MQE188EP-01, which exhibits more dissipated energy than the other walls. Specimens with reinforcement QE188 (Group A) show a slightly larger cumulative dissipated energy than the other walls. There are no differences between Groups B and C because they have a similar amount of the main reinforcement even when the type of reinforcement is different. Prior to the theoretical yielding (displacement at the top of $3 \mathrm{~mm}$ ), a very small amount of energy was dissipated. According to Figure 6(c), the first cycle of every phase dissipates more energy than the subsequent cycles.

Another way to estimate energy dissipation is in terms of damping. In the case of structural elements subjected to cyclic loads, it is common to use the equivalent viscous damping $\left(\xi_{\mathrm{eq}}\right)$ defined in Eq. (2) [19]. 


$$
\xi_{e q}=\frac{1}{4 \pi}\left(\frac{E_{D}}{E_{S 0}}\right)
$$

where $E_{D}$ is the dissipated energy in one cycle and $E_{S 0}$ is the elastic strain energy stored in an equivalent linear elastic system at maximum displacement.

Because a hysteresis curve is not completely symmetrical, $\xi_{\text {eq }}$ was estimated in two ways: one with the positive part of the cycle $\left(\xi_{\mathrm{eq}}{ }^{+}\right)$and the other with the negative part of the cycle $\left(\xi_{\mathrm{eq}}{ }^{-}\right)$(see Figure 6(e)).

Figure 6(e) shows the equivalent viscous damping, which is derived using the negative part of the cycle, in terms of the top displacement. The damping estimated from MQE188EP-01 is different from those estimated from the other walls. The equivalent viscous damping during the first two phases is approximately 0.07 for almost all of the walls except for MQE188EP-01 and MQE188EP-02. These two walls show an equivalent viscous damping of 0.10 .

\subsection{Summary of the experimental results}

Comparing the structural characteristics estimated with respect to Groups A, B, and C, the hysteretic curves obtained from the walls have almost the same tendencies in terms of strength, stiffness degradation, dissipated energy, and equivalent viscous damping, except for MQE188EP-01. This difference in response of MQE188EP-01 could be related to the problems during the construction process of this wall. Although the main reinforcement, which affects the shear resistance, was changed with respect to the Groups, similar response trends for all of the walls were found. In the case of the walls with dowels, only the wall MQE188EP-03 presented a sliding crack at the level of the end of the dowels. These findings indicate that the behaviors of the walls are mainly dominated by flexure because the edge reinforcement remained constant for all of the walls.

\section{CALIBRATION OF THREE-PARAMETER PARK HYSTERETIC MODEL}

The experimental program provided the responses of typical thin RC shear walls that are used in low- and mid-rise buildings in central Peru. Numerical models of these walls are prepared and calibrated using experimental results in this chapter. The nonlinear material response is one of the causes of energy dissipation in hysteretic cycles. Numerical models are prepared in the program IDARC 2D version 7 [20]. The Three-parameter Park hysteretic model is used in order to simulate the nonlinear response under cyclic loading. 
This model was first proposed by Park et al. [21] as part of the original IDARC program. The model considered the stiffness degradation, strength degradation, nonsymmetric response, slip-lock, and tri-linear monotonic envelope. In 1992, Kunnath et al. [22] redefined the parameter "strength degradation" depending on ductility and/or energy. The parameters that define the Three-parameter Park hysteretic model are $\alpha, \beta 1, \beta 2$, and $\gamma$. A graphical description of the influences of each parameter in the hysteretic behavior is presented in Figure 7. The effect of increased stiffness degradation at larger deformation levels is introduced by the parameter $\alpha$. In Figure 7(a), it is shown that the unloading paths on the primary curve target a common point. The value of this new point is equal to $\alpha \mathrm{M}_{\mathrm{y}}$. The parameters $\beta 1$ and $\beta 2$ determine the amount of strength decay as a function of dissipated energy $(\bar{E})$ and ductility $\left(\mu_{\mathrm{c}}\right)$. In Figure $7(\mathrm{~b})$, the value of $\mathrm{M}_{\text {new }}$ is estimated as follows

$$
\begin{array}{r}
M_{\text {new }}=M_{\max }\left(1-\beta 1 * \bar{E}-\beta 2 * \mu_{c}\right) \\
\bar{E}=\frac{A_{T}}{M_{y} * \phi_{y}} \\
\mu_{c}=\frac{\phi_{\max }}{\phi_{y}}
\end{array}
$$

where $A_{T}$ is the total area under the $M-\phi$ loops, $M_{y}$ is the yield moment, $\phi_{y}$ is the yield curvature, $\phi_{\max }$ is the maximum attained curvature, $\mathrm{M}_{\max }$ is the maximum moment attained in a cycle, and $\mathrm{M}_{\text {new }}$ is the maximum moment attained in a subsequent cycle. In case of slip or pinching behavior, the loading paths, upon crossing the zero moment axis, aim a lower target point specified by $\gamma \mathrm{My}$ and retain this smaller stiffness until the path crosses the cracking deformation. Upon crossing the cracking deformation point, the loading paths aim the previous maximum point, unless strength deterioration is also specified, in which case a lower target point is used. (Figure 7(c)). The required parameters to define the hysteretic model are calibrated using the results of the walls MFIEN3EP (Group C) and MQE257EP-01 (Group B) based on the strength, stiffness, energy dissipated, and equivalent viscous damping. The parameters are then validated with the results of walls from the other groups.

\subsection{Modeling of material properties}


To predict the hysteretic curve of a specimen, the nonlinear behaviors of materials should be modeled numerically. As the walls are made of concrete, electro-welded wire mesh, and conventional reinforcement, three nonlinear models are employed in the numerical simulation.

In the case of concrete, unconfined concrete is assumed because the thickness of the walls is small $(100 \mathrm{~mm})$ and does not allow any type of confinement. The Kent and Park model was considered in this study [23]. The tensile strength of concrete was neglected. The value of the compressive strength of concrete ( $\mathrm{f}^{\prime} \mathrm{c}$ ) is estimated from the results of cylindrical specimens mentioned in section 2.1. The concrete modulus (Ec) was determined from f'c following the Peruvian design code E.060 [4]. The ultimate strain was set to be 0.0035 [24], and the other parameters have been estimated using the expressions of Kent and Park [23].

For reinforcement, the uniaxial behavior of the conventional reinforcement and electro-welded wire mesh is modeled by the trilinear model. The behavior is considered to be the same for compressive and tensile stresses. The first part of this curve can be attributed to linear material behavior, for example, the stresses and strains are proportional to each other, whereas the second part is related to the inelastic incursion up to a limit stress. The last part of the model considers the hardening of the material. The modulus of elasticity (Es), yield strength (fy), maximum stress (fu), and hardening strain are estimated from tests presented by Gálvez, A. [2].

\subsection{Modeling of structural elements}

In IDARC 2D, shear wall elements are modeled using macro formulation considering flexural, shear, and axial deformations. Flexural and shear components of the deformation are coupled in the spread plasticity formulation. The Three-parameter Park hysteretic model can be used for both the flexural and shear deformations. Axial deformations are modeled using a linear-elastic spring element uncoupled to the flexural and shear spring elements. To estimate the flexural properties of the wall, IDARC 2D uses the fiber model. The inelastic

shear properties are estimated using the equations presented by Hirosawa [25]. These equations were determined based on test results of 179 specimens, including eight walls with wire-mesh as the main reinforcement.

\subsection{Process of calibration}


As previously mentioned, the results obtained from the walls MFIEN3EP and MQE257EP-01 were used to calibrate the parameters of the Three-parameter Park hysteretic model. A range of values for these parameters is suggested in [21]. Calibration of the numerical model was performed by changing the value of each parameter. The four sets of models were considered, and only one parameter was calibrated in every model. For example, in Set 1, the stiffness degradation $(\alpha)$ was changed from mild to severe degrading. A summary of the variation in parameters and their respective values is shown in Table 7.

These parameters were changed, and the shape of the hysteretic curve from the test was compared with that from the numerical simulation. In addition, stiffness degradations, energy dissipated, cumulative energy dissipated, equivalent viscous damping, and unloading stiffness were compared.

\subsection{Estimation of parameters}

Following the process presented in section 5.3, it was possible to analyze the response sensitivity for every parameter. This analysis was done following a subjective criterion using Figure 8 . Table 8 summarizes the influence of every parameter on the response obtained from the numerical simulation.

From Table 8 , it can be seen that parameter $\alpha$ has no influence on strength and stiffness degradation, but it has influence on the equivalent viscous damping, energy dissipated, and unloading stiffness (see Figure $8(\mathrm{a})$ ). The parameter $\beta 1$ has influence on strength (see Figure 8(b)), equivalent viscous damping, and energy dissipated, but no influence on the stiffness degradation and unloading stiffness. The parameter $\beta 2$ exhibits influence on the strength (see Figure 8(c)), stiffness degradation, energy dissipated, and equivalent viscous damping (see Figure 8(d)). Finally, the parameter $\gamma$ exhibits influence on the energy dissipated and equivalent viscous damping (see Figures $8(\mathrm{e})$ and 8(f)).

To reproduce the results of the test, a new range of values for the parameters were determined as follows: $\alpha<4, \beta 1=0.6,0.15<\beta 2<0.6$, and $0.05<\gamma<0.25$. With this new range, the most suitable values of parameters were estimated to minimize the relative error in the curves for the structural characteristics obtained from the numerical simulation and experiment. The values are $\alpha=0.9, \beta 1=0.6, \beta 2=0.01$, and $\gamma=0.4$. In the case of two of the parameters, $\beta 2$ and $\gamma$, the values out of the range were selected because these two parameters affect more than two characteristics of responses. These new values estimated could be interpreted as the wall exhibits extreme unloading stiffness degradation, severe 
strength degradation based on ductility, no strength degradation based on energy, and mild pinching. The value of $\beta 2$ can also be interpreted as less significant effects of energy-based strength degradation on the numerical estimations. As is presented in Reinhorn et al. [20], the unloading stiffness is a function of both initial stiffness and unloading parameter. In this regard, the proposed value of $\alpha$ by this study is strongly related to the analytical value of the initial stiffness. If we had used the experimental initial value, a different value of $\alpha$ would have been obtained.

Figure 9 compare the response from the numerical simulation using the estimated parameters with the experimental results. In the case of unloading stiffness (Figure 9(f)), the unloading stiffness measured in the test and numerical simulation is significantly different in the first phase. In this phase, the wall remains in the elastic range (see Table 3). Therefore, the initial loading and unloading stiffness are equal. As mentioned in section 4.2, the theoretical stiffness is different from the one obtained from the test because of the drying shrinkage of the concrete. The theoretical stiffness was assigned in the numerical simulation. Based on these facts, the initial estimated-numerical and experimental stiffness are different in Figure 9(f). Figure 10 shows the comparison of hysteretic curves for phase 5 (a) and phase 6 (b). An apparent difference is seen in the unloading stiffness in the last phase, especially on the positive side of the hysteretic curve. The hysteretic curve becomes rounded compared with the initial phase in the experiment, but the numerical model traces the hysteretic behavior as it changes from one linear stage to another. For this reason, the average unloading stiffness was estimated in the experiment. The average unloading stiffness is similar with the value of the unloading stiffness obtained from the numerical simulation.

Following the same calibration procedure for the wall MQE257EP-01, the parameters $\alpha, \beta 1, \beta 2$, and $\gamma$ presented similar values to those found for the wall MFIENE3P. Table 9 shows the estimated parameters, and Figure 11 shows the comparison of the structural characteristics (hysteretic curve, skeleton curve, lateral stiffness and dissipated energy) obtained from the test and numerical simulation for the wall MQE257EP-01. The results of the numerical simulation are in good agreement with those of the experiment in terms of the hysteretic curve, skeleton curve, lateral stiffness, energy dissipated, and unloading stiffness. In the case of equivalent viscous damping, the correlation is good until phase 5 (displacement at the top equal to $12 \mathrm{~mm}$ ). The estimations coincided with the experimental results. 
In general, the responses from the numerical simulation are in good agreement with those from the test. In the case of stiffness degradation and unloading stiffness in the elastic range, there is no good agreement because of the difference in the initial stiffness produced by the cracking of a wall prior to the test. Hysteretic curves are in good agreement until displacement at the top reaches $12 \mathrm{~mm}$. In all cases, the equivalent viscous damping exhibits medium dispersion.

\subsection{Validation of parameters based on the results of other walls}

A set of parameters that define the Three-parameter Park hysteretic model was calibrated using the results from the test on the wall with conventional reinforcement (Group C) and on the wall of Group B (MQE257EP-01). The applicability of those values is evaluated using the results from other tests. This validation was performed comparing the same structural characteristics presented in section 5.4.

Figure 12 shows the comparison of the experimental hysteretic curves and those from the numerical simulation for the other five walls. The numerical simulation of MQE188EP-01 shows low correlation with the hysteretic curve from the test. The low correlation was expected for the wall because of the reasons mentioned in the previous section. As for the other four walls, the numerical simulation resulted in good estimations compared to the experimental results. The lateral stiffness, energy dissipated, and unloading stiffness obtained from the hysteretic curves also show good correlations, whereas the equivalent viscous damping presented larger dispersions.

\section{SUMMARY AND CONCLUSIONS}

The results of static cyclic tests of seven full-scale thin RC shear walls carried out at CISMID were presented. The parameters to define the Three-parameter Park hysteretic model were estimated and validated using the hysteretic curves and characteristics of the

responses. From the analysis of test results and the process of calibration and validation, the following conclusions can be drawn:

Although the walls have different main reinforcement, most of the curves show a similar tendency in terms of strength, stiffness degradation, energy dissipated, and equivalent viscous damping. This could indicate that the behavior of the walls is governed by flexure because the only variant in all walls was the main reinforcement (shear reinforcement); the edge reinforcement remained constant.

The walls with low reinforcement ratio, Group A, exhibit a significant deformation 
capacity although the type of reinforcement consists of non-ductile members.

The walls reinforced with low reinforcement ratio, Group A, exhibit the lowest maximum strength, whereas the wall with higher reinforcement ratio, Group C, exhibits the highest maximum strength. The walls reinforced with electro-welded wire mesh show low strength degradation after the top displacement of $12 \mathrm{~mm}$, which corresponds to an imposed displacement ductility demand of 4.79 and 4.24 for the walls MQE188EP and MQE257EP, respectively, whereas it was not observed in the result of the wall with ductile bars.

All specimens show almost the same level of dissipated energy. The walls of Group A exhibit a slightly larger cumulative dissipated energy than the other walls. In every phase, the walls dissipated more energy in the first cycle than in the subsequent cycles.

Equivalent viscous damping exhibits more dispersion than other characteristics. The mean value is 0.07 for the first two phases (before yielding) except for MQE188EP-01 and MQE188EP-02. These two walls show average values of 0.10 .

From the process of calibrating the numerical model, it was found that the parameter $\alpha$ has an influence on equivalent viscous damping, energy dissipated, and unloading stiffness; the parameter $\beta 1$ has an influence on strength, equivalent viscous damping, and energy dissipated; and the parameter $\beta 2$ exhibits an influence on strength, stiffness degradation, energy dissipated, and equivalent viscous damping. Finally, the parameter $\gamma$ exhibits an influence on the energy dissipated and equivalent viscous damping. According to the values of the validated parameters, the walls are interpreted to show extreme unloading stiffness degradation, severe strength degradation based on ductility, and no strength degradation based on energy and mild pinching. The results of the numerical simulation are in good agreement with the experimental results.

The calibrated model can be used to represent the hysteretic behavior of thin RC Peruvian shear walls numerically. The model allows the assessment of behavior of existing structures, and damage to these walls due to earthquakes will be investigated in a future study.

\section{ACKNOWLEDGMENTS}

The authors would like to express their sincere gratitude to the Japan Science and Technology Agency (JST) and Japan International Cooperation Agency (JICA) under the SATREPS project "Enhancement of earthquake and tsunami disaster mitigation technology in Peru" and to the anonymous reviewers who made valuable suggestions to increase the technical quality of the paper. 


\section{REFERENCES}

[1] EERI (2010) “The Mw 8.8 Chile Earthquake of February 27, 2010”. Special Earthquake Report June 2010.

[2] Gálvez, V.; Burgos, M. and Ortiz, A. (2008) "Proposal of reduction factor for seismic forces in structural systems composed by walls reinforced with electro-welded wire mesh and ductile bars". Lima, Peru (In Spanish).

[3] Ministry of Housing Peru (2003) "National Technical Standard E-030 - Earthquake Resistant Design". Lima, Peru. (In Spanish).

[4] Ministry of Housing Peru (2009) "National Technical Standard E-060 - Reinforced Concrete Design". Lima, Peru. (In Spanish).

[5] Pilakoutas, K. and Elnashai, A. S. (1995) "Cyclic Behavior of RC Cantilever Walls, Part I: Experimental Results”. ACI Structural Journal, V. 92, No. 3, May-June 1995, pp. 271-281.

[6] Pilakoutas, K. and Elnashai, A. S. (1995) "Cyclic Behavior of RC Cantilever Walls, Part II: Discussions and Theoretical Comparisons". ACI Structural Journal, V. 92, No. 4, July-August 1995, pp. $425-433$.

[7] Tasnimi, A. (2000) "Strength and deformation of mid-rise shear walls under load reversal". Engineering Structures 22, pp. 311-322.

[8] Riva, P.; Meda, A. and Giuriani, E. (2003) "Cyclic behaviour of a full scale RC structural wall". Engineering Structures 25, pp. 835-845.

[9] Shaingchin, S.; Lukkunaprasit, P. and Wood, S. (2007) "Influence of diagonal web reinforcement on cyclic behavior of structural walls". Engineering Structures 29, pp. 498-510.

[10] Tang, Y. and Zhang, J. (2011) "Probabilistic seismic demand analysis of a slender RC shear wall considering soil-structure interaction effects”. Engineering Structures 33, pp. 218-229.

[11] Gonzales, H. and López-Almansa, F. (2012) "Seismic performance of buildings with thin RC bearing walls". Engineering Structures 34, pp. 244-258.

[12] Zavala, C. (2004) "Test on walls and a one-floor house reinforced with electro-wire mesh UNICO/FORSA/PRODAC”. Research report. Japan-Peru Center for Earthquake Engineering Research and Disaster Mitigation. Lima, Peru (in Spanish).

[13] PRODAC (2008) “Technical manual of electro welded mesh”. Lima, Peru (In Spanish).

[14] Flores, E.; Alcocer, S.; Carrillo, J.; Sanchez, A.; Uribe, R. and Ponce, A. (2007) “Testing of concrete walls with different aspect ratios and low rates of reinforcement for use in housing". Mexican Society of Seismic Engineering, National Congress of Earthquake Engineering, Ixtapa Zihuatanejo, Guerrero, Mexico. 
[15] Tayra, J. (2009) "Seismic performance of reinforced concrete wall-system with electro-welded mesh". Master thesis submitted in partial fulfillment of the requirement for the Degree of Master in Disaster Management, Building Research Institute, Tsukuba, Japan.

[16] Lopes, M.S. (2001) "Experimental shear dominated response of RC wall. Par II: Discussion of results and design implication". Engineering Structures 23, pp. 564-574.

[17] Park, Y.J.; Reinhorn, A. and Kunnath, K. (1988) "Seismic damage analysis of reinforced concrete buildings". Proceedings of Ninth World Conference on Earthquake Engineering. August 2-9, Tokyo-Kyoto, Japan (Vol. VII).

[18] Sittipunt, C.; Wood, S.; Lukkunaprasit, P. and Pattararattanakul, P. (2001) "Cyclic behavior of reinforced concrete structural walls with diagonal web reinforcement”. ACI Structural Journal Vol. 98 No. 4, July-August. 2001, pp. 554-562.

[19] Chopra, A. (2007) "Dynamic of Structures - Theory and applications to earthquake engineering". Third Edition. Pearson Prentice Hall, New Jersey.

[20] Reinhorn, A.M.; Roh, H.; Sivaselvan, M.; Kunnath, S.K.; Valles, R.E.; Madan, A.; Li, C.; Lobo, R. and Park, Y.J. (2009) "IDARC2D Version 7.0: A Program for the Inelastic Damage Analysis of Structures”. Technical Report MCEER-09-0006, State University of New York at Buffalo.

[21] Park, Y.J.; Reinhorn, A.M. and Kunnath, S.K. (1987) "IDARC Inelastic Damage Analysis of Reinforced Concrete Frame-Shear-Wall Structures". Technical Report NCEER-87-0008, State University of New York at Buffalo.

[22] Kunnath, S.K.; Reinhorn, A.M. and Lobo, R.F. (1992) "IDARC Version 3.0 A Program for the Inelastic Damage Analysis of Reinforced Concrete Structures”. Technical Report NCEER-92-0022, State University of New York at Buffalo.

[23] Kent, D.C. and Park, R.R. (1971) "Flexural members with confined concrete". Journal of the Structural Division, ASCE, 97:7, pp. 1969-1990.

[24] Deng, H.Z.; Chang, Y.Y.; Lau, D.T.; Ostovari, S. and Tsai, K.C. (2003) “A simplified approach for nonlinear response analysis of composite structural members". Proceedings of the International Workshop on Steel and Concrete Composite Construction, Taipei, Taiwan. pp. 207-216.

[25] Hirosawa, M. (1975) "Past experimental results on reinforced concrete shear walls and analysis on them”. Building Research Institute, Ministry of Construction, Japan, Kenchiku Kenkyu Shiryo, No. 6, March, Tokyo. 


\section{CAPTIONS}

Table 1. Distribution of reinforcement in walls

Table 2. Characteristics of electro-welded wire mesh

Table 3. Loading history for the wall MFIEN3EP

Table 4. Progression of cracking in specimens of Group A, B and C

Table 5. Summary of properties of walls: maximum strengths $\left(\mathrm{F}_{\max }\right)$, maximum moment developed during the first phase $\left(\mathrm{M}_{1}\right.$ Phase $)$, theoretical moment for flexural cracking $\left(\mathrm{M}_{\mathrm{CR}}\right)$, estimation of initial stiffness ( $\left.\mathrm{K}_{\text {ini-eq }}\right)$ and theoretical initial stiffness $\left(\mathrm{K}_{\text {Theo. }}\right)$

Table 6. Variation in initial stiffness for MFIEN3EP before yielding

Table 7. Variation in parameters of the Three-parameter Park hysteretic model for calibration process

Table 8 . Influence of every parameter on the response of the wall

Table 9. Comparison of calibrated parameters for walls MFIEN3EP and MQE257EP-01

Fig. 1. Stress-strain relationships for electro-welded wire mesh [2]

Fig. 2. Geometry and reinforcement details of walls: (a) dimensions of the specimens (in $\mathrm{mm}$ ), reinforcement of walls, (b) MEQ188EP-01 and 02, (c) MEQ188EP-03, and (d) MFIEN3EP

Fig. 3. (a) Instrumentation and (b) load frame of walls

Fig. 4. Overall hysteretic responses of walls, (a) MQE188EP-01, (b) MQE188EP-02; (c) MQE188EP-03, (d) MQE257EP-01, (e) MQE257EP-02, (f) MQE257EP-03, and (g) MFIEN3EP

Fig. 5. Final state of walls a) MQE188EP-01, b) MQE257EP-02, and c) MFIEN3EP [12]

Fig. 6. Structural characteristics: (a) Skeleton curves, (b) lateral equivalent stiffness, (c) energy dissipated, (d) cumulative dissipated energy and (e) equivalent viscous damping with respect to displacement at the top of the walls

Fig. 7. Graphical representations of the influences of (a) $\alpha$, (b) $\beta 1, \beta 2$, and (c) $\gamma$ on the hysteretic curve

Fig. 8. Influence of parameters in structural characteristics: (a) $\alpha$ on unloading stiffness, (b) $\beta 1$ on strength, (c) $\beta 2$ on strength, (d) $\beta 2$ on equivalent viscous damping, (e) $\gamma$ on energy dissipated and (f) $\gamma$ on equivalent viscous damping

Fig. 9. Comparison of test results versus numerical simulation for the wall MFIEN3EP: a) hysteresis curves, (b) stiffness degradation, (c) cumulative energy dissipated, (d) dissipated energy, (e) equivalent viscous damping and (f) unloading stiffness

Fig. 10. Comparison of hysteretic curves for wall MFIEN3EP in a) phase 5 and b) phase 6

Fig. 11. Comparison of the results from the test and numerical simulation for MQE257EP-01 with respect to a) hysteretic curve, b) skeleton curve, c) lateral stiffness and d) dissipated energy

Fig. 12. Comparison of the hysteretic curves obtained from the numerical simulation and tests for the 
walls: a) MQE188EP-01, c) MQE188EP-02, c) MQE188EP-03, and d) MQE257EP-03 
Table 1. Distribution of reinforcement in walls

\begin{tabular}{|c|c|c|c|c|c|c|}
\hline Group & Wall & $\begin{array}{c}\text { Main } \\
\text { Reinforcement }\end{array}$ & $\rho_{\mathrm{h}}{ }^{1}$ & $\rho_{\mathrm{v}}^{2}$ & Dowels & $\begin{array}{c}\text { Edge } \\
\text { Reinforcement }\end{array}$ \\
\hline \multirow[t]{2}{*}{ A } & $\begin{array}{l}\text { MQE188EP-01 } \\
\text { MQE188EP-02 }\end{array}$ & QE188 & 0.0018 & 0.0018 & QE84/188 3 & \multirow{5}{*}{$3 \# 4{ }^{4}$} \\
\hline & MQE188EP-03 & & & & \#3@ 250 & \\
\hline \multirow[t]{2}{*}{ B } & $\begin{array}{l}\text { MQE257EP-01 } \\
\text { MQE257EP-02 }\end{array}$ & QE257 & 0.00257 & 0.00257 & QE84/257 & \\
\hline & MQE257EP-03 & & & & \#3@250 & \\
\hline $\mathrm{C}$ & MFIEN3EP & $\# 3^{5} @ 250$ & 0.00284 & 0.00284 & \#3@250 & \\
\hline
\end{tabular}

${ }^{1}$ Horizontal reinforcement ratio

${ }^{2}$ Vertical reinforcement ratio

${ }^{3}$ QE84/188: bars with a diameter of $4 \mathrm{~mm}$ in the horizontal direction and bars with a diameter of $6 \mathrm{~mm}$ in the vertical direction, both spaced at $150 \mathrm{~mm}$

${ }^{4}$ \#4: corrugated bars with a diameter of $12.7 \mathrm{~mm}$

${ }^{5} \# 3$ : corrugated bars with a diameter of $9.5 \mathrm{~mm}$ 
Table 2. Characteristics of electro-welded wire mesh

\begin{tabular}{cccc}
\hline Mesh & $\begin{array}{c}\text { Diameter } \\
\text { of bars } \\
(\mathrm{mm})\end{array}$ & $\begin{array}{c}\text { Spacing } \\
\text { of bars } \\
(\mathrm{mm})\end{array}$ & $\begin{array}{c}\text { Density } \\
\left(\mathrm{mm}^{2} / \mathrm{m}\right)\end{array}$ \\
\hline QE188 & 6 & 150 & 188 \\
QE257 & 7 & 150 & 257 \\
QE84 & 4 & 150 & 84 \\
\hline
\end{tabular}

${ }^{1}$ Reinforcement area per unit length of wall 
Table 3. Loading history for the wall MFIEN3EP

\begin{tabular}{ccccccc}
\hline \multirow{2}{*}{ Wall } & Phase & $\begin{array}{c}\text { No. of } \\
\text { Cycles }\end{array}$ & $\begin{array}{c}\text { Distortion } \\
(-)\end{array}$ & $\begin{array}{c}\Delta_{\mathrm{TOP}}{ }^{1} \\
(\mathrm{~mm})\end{array}$ & $\begin{array}{c}\Delta_{\mathrm{y}}{ }^{2} \\
(\mathrm{~mm})\end{array}$ & $\begin{array}{c}\Delta_{\mathrm{TOP}} / \Delta_{\mathrm{y}} \\
(-)\end{array}$ \\
\hline \multirow{4}{*}{ MFIEN3EP } & 1 & 3 & $1 / 3200$ & 0.75 & & 0.26 \\
& 2 & 3 & $1 / 1600$ & 1.5 & & 0.51 \\
& 4 & 3 & $1 / 800$ & 3 & & 1.02 \\
& 5 & 3 & $1 / 400$ & 6 & & 2.93 \\
& 6 & 3 & $1 / 200$ & 12 & & 4.10 \\
& & 3 & $1 / 100$ & 24 & & 8.19 \\
\hline
\end{tabular}

${ }^{1}$ Target displacement at top of wall in every phase

${ }^{2}$ Theoretical yield displacement for the wall MFIEN3EP 
Table 4. Progression of cracking in specimens of Group A, B and C

\begin{tabular}{|c|c|c|c|c|c|c|c|}
\hline \multirow{2}{*}{ Phase } & \multicolumn{3}{|c|}{ Group A } & \multicolumn{3}{|c|}{ Group B } & \multirow{2}{*}{$\begin{array}{c}\text { Group C } \\
\text { MFIEN3EP }\end{array}$} \\
\hline & MQE188EP-01 & MQE188EP-02 & MQE188EP-03 & MQE257EP-01 & MQE257EP-02 & MQE257EP-03 & \\
\hline 1 & $\begin{array}{l}\text { Longitudinal cracks } \\
\text { appear along the base } \\
\text { and some near the } \\
\text { lower corners }\end{array}$ & $\begin{array}{l}\text { Longitudinal cracks } \\
\text { appear along the base }\end{array}$ & $\begin{array}{l}\text { Longitudinal cracks } \\
\text { appear along the base }\end{array}$ & $\begin{array}{l}\text { Longitudinal cracks } \\
\text { appear along the base }\end{array}$ & - & - & $\begin{array}{l}\text { Longitudinal cracks } \\
\text { appear along the base }\end{array}$ \\
\hline 2 & $\begin{array}{l}\text { Flexure cracks } \\
\text { initiate }\end{array}$ & - & $\begin{array}{l}\text { Flexure cracks } \\
\text { initiate }\end{array}$ & $\begin{array}{c}\text { Flexure cracks } \\
\text { initiate in an almost } \\
\text { diagonal pattern from } \\
\text { edges }\end{array}$ & $\begin{array}{l}\text { Longitudinal cracks } \\
\text { appear along the base }\end{array}$ & $\begin{array}{l}\text { Longitudinal cracks } \\
\text { appear along the base }\end{array}$ & $\begin{array}{c}\text { Cracks along the base } \\
\text { accentuate }\end{array}$ \\
\hline 3 & $\begin{array}{c}\text { Flexural cracks } \\
\text { accentuate in an } \\
\text { almost diagonal } \\
\text { pattern }\end{array}$ & $\begin{array}{l}\text { Flexure cracks } \\
\text { initiate }\end{array}$ & $\begin{array}{c}\text { Flexural cracks } \\
\text { accentuate in an } \\
\text { almost diagonal } \\
\text { pattern }\end{array}$ & $\begin{array}{l}\text { Flexural cracks } \\
\text { accentuate }\end{array}$ & $\begin{array}{c}\text { Flexure cracks } \\
\text { initiate in an almost } \\
\text { diagonal pattern from } \\
\text { edges }\end{array}$ & $\begin{array}{c}\text { Flexure cracks } \\
\text { initiate in an almost } \\
\text { diagonal pattern from } \\
\text { edges }\end{array}$ & $\begin{array}{c}\text { Flexure cracks } \\
\text { initiate in an almost } \\
\text { diagonal pattern from } \\
\text { edges }\end{array}$ \\
\hline 4 & $\begin{array}{l}\text { Flexural cracks } \\
\text { accentuate in an } \\
\text { almost diagonal } \\
\text { pattern }\end{array}$ & $\begin{array}{l}\text { Flexural cracks } \\
\text { accentuate in an } \\
\text { almost diagonal } \\
\text { pattern }\end{array}$ & $\begin{array}{c}\text { Flexural cracks } \\
\text { accentuate in an } \\
\text { almost diagonal } \\
\text { pattern }\end{array}$ & $\begin{array}{c}\text { Flexural cracks } \\
\text { accentuate }\end{array}$ & $\begin{array}{c}\text { Flexural cracks } \\
\text { accentuate and } \\
\text { crushing of corners } \\
\text { initiates }\end{array}$ & $\begin{array}{l}\text { Flexural cracks } \\
\text { accentuate }\end{array}$ & $\begin{array}{c}\text { Flexural cracks } \\
\text { accentuate }\end{array}$ \\
\hline 5 & $\begin{array}{c}\text { Cracking } \\
\text { concentrates along } \\
\text { the base and wall } \\
\text { slips }\end{array}$ & $\begin{array}{l}\text { Crushing of corners } \\
\text { initiates and cracks } \\
\text { propagate to } \\
\text { foundation. Wall slips }\end{array}$ & $\begin{array}{l}\text { Sliding cracks appear } \\
\text { at the end of dowels }\end{array}$ & $\begin{array}{c}\text { Crushing of corners } \\
\text { initiates }\end{array}$ & $\begin{array}{c}\text { Crushing of corners } \\
\text { accentuates }\end{array}$ & $\begin{array}{c}\text { Flexural cracks } \\
\text { accentuate and } \\
\text { crushing of corners } \\
\text { initiates }\end{array}$ & $\begin{array}{c}\text { Flexural cracks } \\
\text { accentuate }\end{array}$ \\
\hline 6 & ${ }^{2}$ & 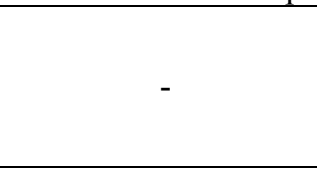 & $\begin{array}{c}\text { Increase of sliding } \\
\text { crack (thickness of } 10 \\
\mathrm{~mm})\end{array}$ & $\begin{array}{l}\text { Crushing of corners } \\
\text { with wall slip }\end{array}$ & Failure of the corner & $\begin{array}{c}\text { Failure of the corner } \\
\text { of wall }\end{array}$ & $\begin{array}{c}\text { Flexural cracks } \\
\text { accentuate and } \\
\text { crushing of corners } \\
\text { initiates }\end{array}$ \\
\hline
\end{tabular}


Table 5. Summary of properties of walls: maximum strengths $\left(\mathrm{F}_{\max }\right)$, maximum moment developed during the first phase $\left(\mathrm{M}_{1}\right.$ Phase $)$, theoretical moment for flexural cracking $\left(\mathrm{M}_{\mathrm{CR}}\right)$, estimation of initial stiffness $\left(\mathrm{K}_{\text {ini-eq }}\right)$ and theoretical initial stiffness $\left(\mathrm{K}_{\text {Theo. }}\right)$

\begin{tabular}{|c|c|c|c|c|c|c|c|c|c|}
\hline Group & Wall & $\begin{array}{l}F_{\text {Max }} \\
(\mathrm{kN})\end{array}$ & $\begin{array}{l}\mathrm{M}_{1 \text { Phase }} \\
(\mathrm{kNm})\end{array}$ & $\begin{array}{c}\mathrm{M}_{\mathrm{CR}} \\
(\mathrm{kNm})\end{array}$ & $\begin{array}{c}\mathrm{K}_{\mathrm{ini}}^{+} \\
(\mathrm{kN} / \mathrm{mm})\end{array}$ & $\begin{array}{c}\mathrm{K}_{\mathrm{ini}}^{-} \\
(\mathrm{kN} / \mathrm{mm})\end{array}$ & $\begin{array}{c}\mathrm{K}_{\text {ini-eq }} \\
(\mathrm{kN} / \mathrm{mm})\end{array}$ & $\begin{array}{c}\mathrm{K}_{\text {Theo. }} \\
(\mathrm{kN} / \mathrm{mm})\end{array}$ & $\mathrm{K}_{\text {ini-eq }} / \mathrm{K}_{\text {Theo. }}$ \\
\hline \multirow{3}{*}{ A } & MQE188EP-01 & 355 & 346.37 & & 160.78 & 170.68 & 165.4 & & 0.48 \\
\hline & MQE188EP-02 & 379 & 375.93 & & 169.82 & 170.79 & 170.33 & & 0.50 \\
\hline & MQE188EP-03 & 419 & 397.16 & & 181.14 & 201.46 & 190.77 & & 0.56 \\
\hline \multirow{3}{*}{ B } & MQE257EP-01 & 436 & 406.17 & 406.55 & 167.85 & 216.07 & 189.64 & 342.02 & 0.55 \\
\hline & MQE257EP-02 & 416 & 413.82 & & 227.44 & 149.84 & 185.46 & & 0.54 \\
\hline & MQE257EP-03 & 436 & 431.23 & & 175.64 & 215.26 & 194.29 & & 0.57 \\
\hline $\mathrm{C}$ & MFIEN3EP & 456 & 348.51 & & 145.99 & 217.62 & 176.33 & & 0.52 \\
\hline
\end{tabular}


Table 6. Variation in initial stiffness for MFIEN3EP before yielding

\begin{tabular}{ccccc}
\hline Phase & $\begin{array}{c}\text { Cycle } \\
\text { No. }\end{array}$ & $\begin{array}{c}\mathrm{K}_{\text {ini }}{ }^{+} \\
(\mathrm{kN} / \mathrm{mm})\end{array}$ & $\begin{array}{c}\mathrm{K}_{\text {ini }}{ }^{-} \\
(\mathrm{kN} / \mathrm{mm})\end{array}$ & $\begin{array}{c}\mathrm{K}_{\text {ini-eq }} \\
(\mathrm{kN} / \mathrm{mm})\end{array}$ \\
\hline \multirow{2}{*}{1} & 1 & 153.81 & 230.43 & 185.57 \\
& 2 & 133.45 & 235.23 & 174.24 \\
& 3 & 150.70 & 187.20 & 169.18 \\
\hline \multirow{2}{*}{2} & 1 & 117.85 & 232.01 & 161.57 \\
& 2 & 103.43 & 218.37 & 150.56 \\
& 3 & 87.84 & 189.74 & 129.91 \\
\hline
\end{tabular}


Table 7. Variation in parameters of the Three-parameter Park hysteretic model for calibration process

\begin{tabular}{|c|c|c|c|c|c|c|c|c|c|}
\hline \multirow[t]{2}{*}{ Set } & \multirow[t]{2}{*}{ Model } & \multicolumn{2}{|c|}{$\begin{array}{c}\text { Stiffness } \\
\text { degradation } \\
\alpha\end{array}$} & \multicolumn{2}{|c|}{$\begin{array}{c}\text { Strength degradation - } \\
\text { Ductility Based } \\
\beta 1\end{array}$} & \multicolumn{2}{|c|}{$\begin{array}{c}\text { Strength degradation - } \\
\text { Energy Based } \\
\beta 2\end{array}$} & \multicolumn{2}{|c|}{$\begin{array}{c}\text { Pinching } \\
\text { behavior } \\
\gamma\end{array}$} \\
\hline & & Value & Implication & Value & Implication & Value & Implication & Value & Implication \\
\hline 0 & 0 & 200 & N.D. & 0.01 & N.D. & 0.01 & N.D. & 1 & N.D. \\
\hline 1 & $\begin{array}{l}1 \\
2 \\
3\end{array}$ & $\begin{array}{l}15 \\
10 \\
4\end{array}$ & $\begin{array}{l}\text { Mi.D. } \\
\text { Mo.D. } \\
\text { S.D. }\end{array}$ & $\begin{array}{l}0.01 \\
0.01 \\
0.01\end{array}$ & N.D. & $\begin{array}{l}0.01 \\
0.01 \\
0.01\end{array}$ & N.D. & $\begin{array}{l}1 \\
1 \\
1\end{array}$ & N.D. \\
\hline 2 & $\begin{array}{l}4 \\
5 \\
6\end{array}$ & $\begin{array}{l}200 \\
200 \\
200\end{array}$ & N.D. & $\begin{array}{c}0.15 \\
0.3 \\
0.6\end{array}$ & $\begin{array}{l}\text { Mi.D. } \\
\text { Mo.D. } \\
\text { S.D. }\end{array}$ & $\begin{array}{l}0.01 \\
0.01 \\
0.01\end{array}$ & N.D. & $\begin{array}{l}1 \\
1 \\
1\end{array}$ & N.D. \\
\hline 3 & $\begin{array}{l}7 \\
8 \\
9\end{array}$ & $\begin{array}{l}200 \\
200 \\
200\end{array}$ & N.D. & $\begin{array}{l}0.01 \\
0.01 \\
0.01\end{array}$ & N.D. & $\begin{array}{c}0.08 \\
0.15 \\
0.6\end{array}$ & $\begin{array}{l}\text { Mi.D. } \\
\text { Mo.D. } \\
\text { S.D. }\end{array}$ & $\begin{array}{l}1 \\
1 \\
1\end{array}$ & N.D. \\
\hline 4 & $\begin{array}{l}10 \\
11 \\
12\end{array}$ & $\begin{array}{l}200 \\
200 \\
200\end{array}$ & N.D. & $\begin{array}{l}0.01 \\
0.01 \\
0.01\end{array}$ & N.D. & $\begin{array}{l}0.01 \\
0.01 \\
0.01\end{array}$ & N.D. & $\begin{array}{l}0.4 \\
0.25 \\
0.05\end{array}$ & $\begin{array}{c}\text { Mi.D. } \\
\text { Mo.D. } \\
\text { S.D. }\end{array}$ \\
\hline
\end{tabular}

Notation: N.D.: No degrading, Mi.D.: Mild degrading, Mo.D.: Moderate degrading, S.D.:

Severe degrading 
Table 8. Influence of every parameter on the response of the wall

\begin{tabular}{|c|c|c|c|c|c|c|c|}
\hline Parameter & Implication & Strength & $\mathrm{K}^{ \pm}$ & $\mathrm{K}_{\mathrm{eq}}$ & $\zeta_{\text {eq }}$ & $\mathrm{E}_{\mathrm{D}}$ & $\begin{array}{c}\text { Unloading } \\
\text { stiffness }\end{array}$ \\
\hline \multirow{3}{*}{$\alpha$} & Mi.D. & - & - & - & $\mathrm{X}$ & $\mathrm{X}$ & $\mathrm{X}$ \\
\hline & Mo.D. & - & - & - & $\mathrm{X}$ & $\mathrm{X}$ & $\mathrm{X}$ \\
\hline & S.D. & - & - & - & $\mathrm{X}$ & $\mathrm{X}$ & $\mathrm{X}$ \\
\hline \multirow{3}{*}{$\beta 1$} & Mi.D. & $X$ & - & - & - & - & - \\
\hline & Mo.D. & $X$ & - & - & - & - & - \\
\hline & S.D. & $X$ & - & - & - & - & - \\
\hline \multirow{3}{*}{$\beta 2$} & Mi.D. & $X$ & $X$ & $X$ & $X$ & $X$ & - \\
\hline & Mo.D. & $X$ & $X$ & $X$ & $X$ & $X$ & - \\
\hline & S.D. & $X$ & $\mathrm{X}$ & $X$ & $X$ & $X$ & - \\
\hline \multirow{3}{*}{$\gamma$} & Mi.D. & - & - & - & $X$ & $X$ & - \\
\hline & Mo.D. & - & - & - & $X$ & $X$ & - \\
\hline & S.D. & - & - & - & $\mathrm{X}$ & $\mathrm{X}$ & - \\
\hline
\end{tabular}

Notation: N.D.: No degrading, Mi.D.: Mild degrading, Mo.D.: Moderate degrading, S.D.: Severe degrading, X: The parameter has influence on the structural characteristic. 
Table 9. Comparison of calibrated parameters for walls MFIEN3EP and MQE257EP-01

\begin{tabular}{ccccc}
\hline Specimen & $\alpha$ & $\beta 1$ & $\beta 2$ & $\gamma$ \\
\hline MFIEN3EP & 0.90 & 0.60 & 0.01 & 0.40 \\
MQE257EP-01 & 0.85 & 0.55 & 0.01 & 0.45 \\
\hline
\end{tabular}




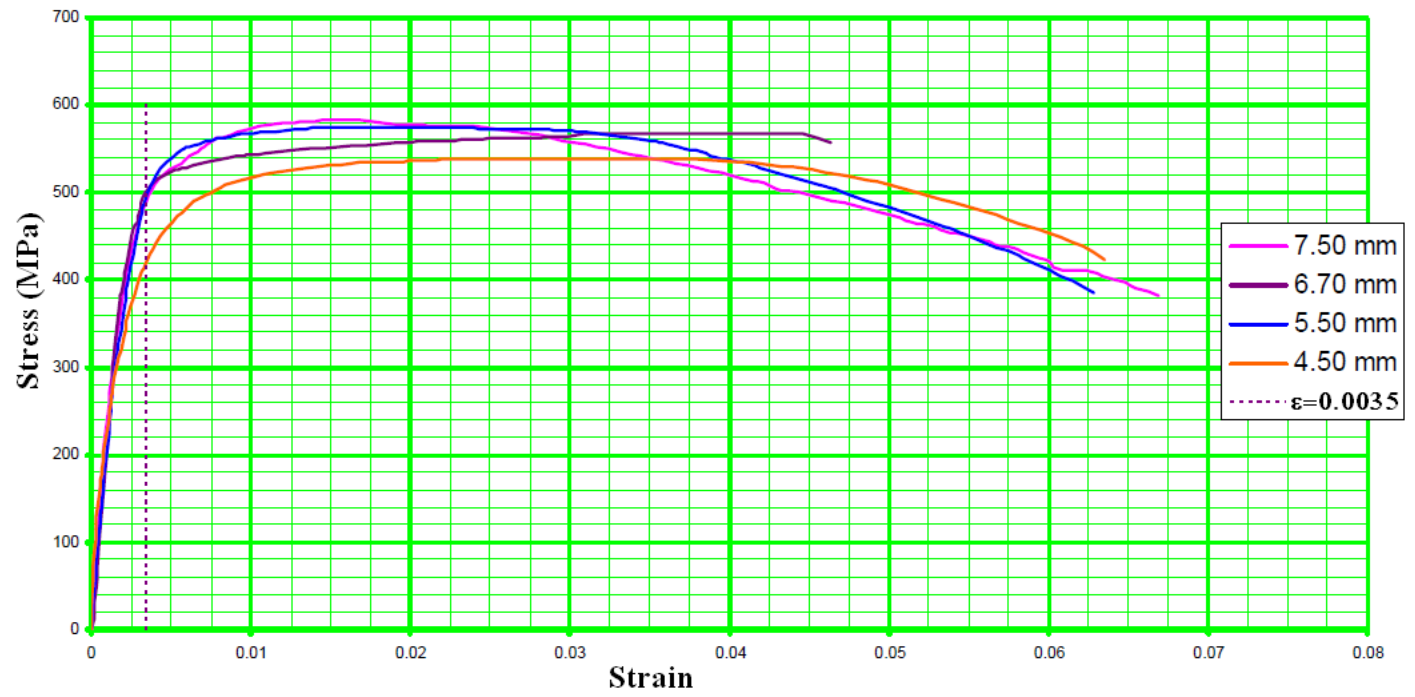

Fig. 1. Stress-strain relationships for electro-welded wire mesh [2] 

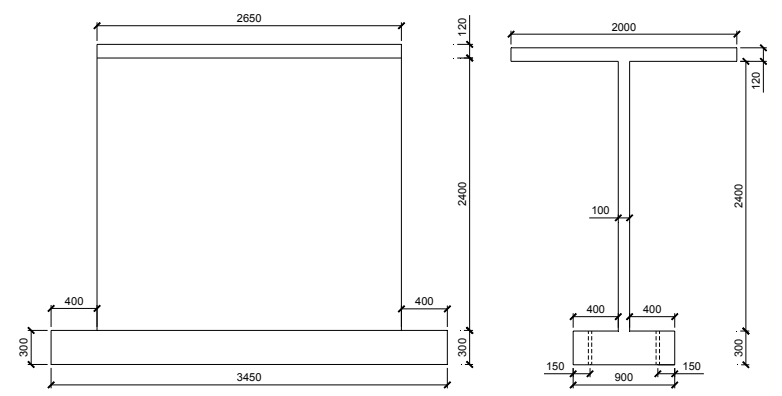

(a)
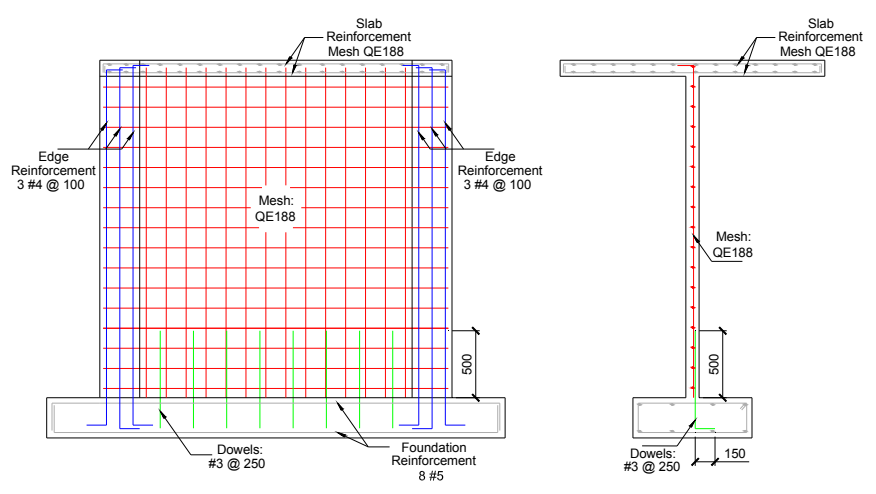

(c)

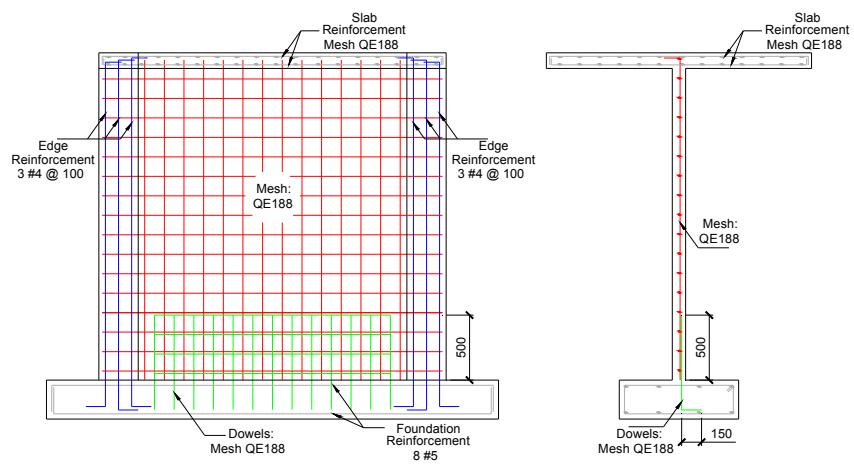

(b)

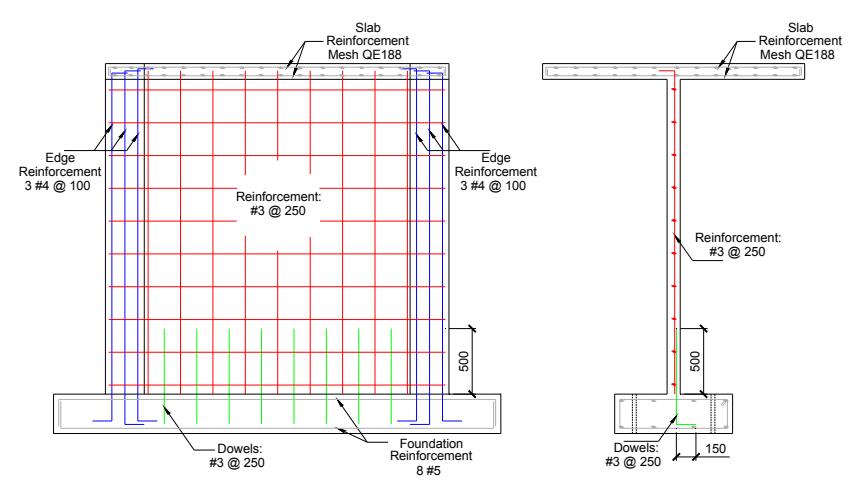

(d)

Fig. 2. Geometry and reinforcement details of walls: (a) dimensions of the specimens (in $\mathrm{mm}$ ), reinforcement of walls, (b) MEQ188EP-01 and 02, (c) MEQ188EP-03, and (d) MFIEN3EP 


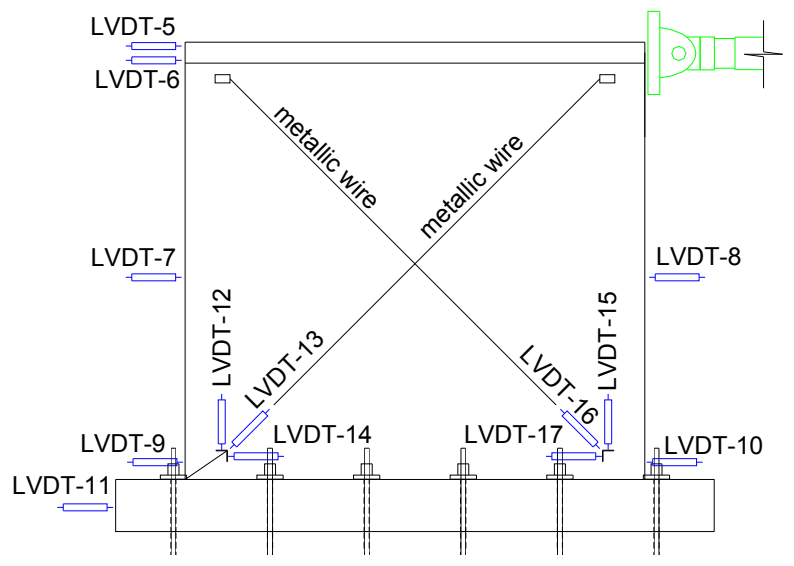

(a)

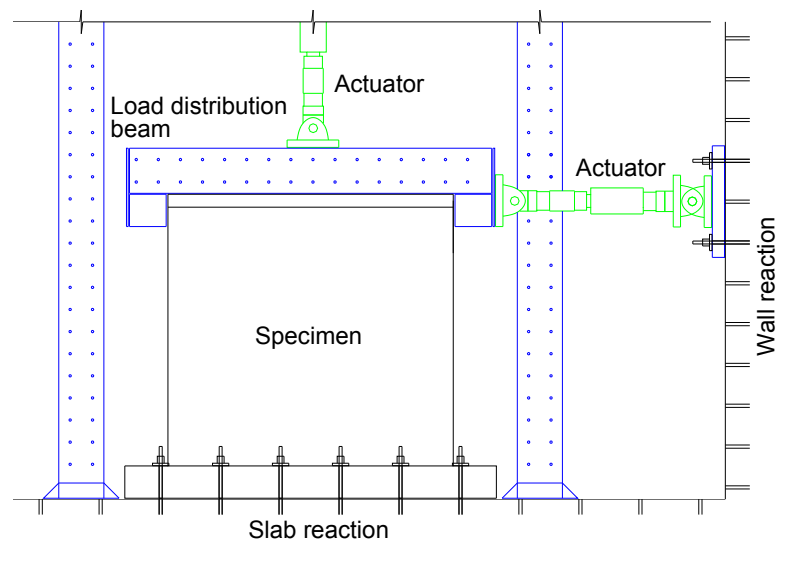

(b)

Fig. 3. (a) Instrumentation and (b) load frame of walls 


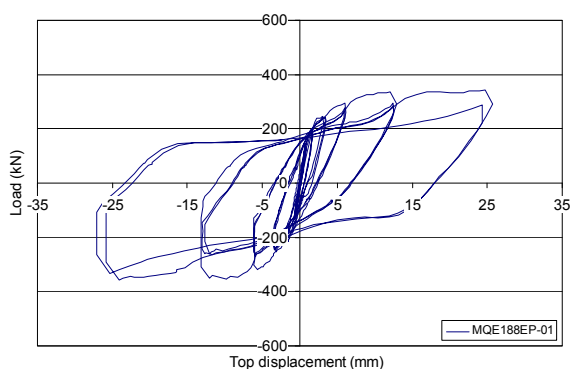

(a)

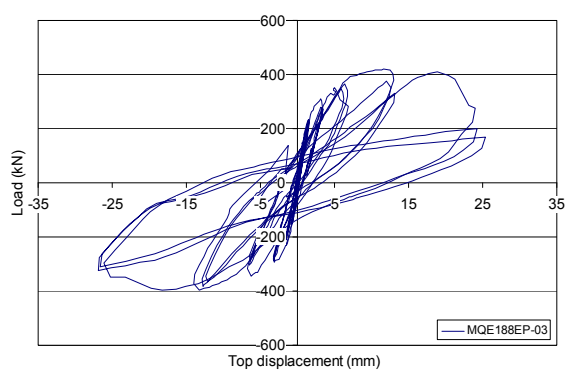

(c)

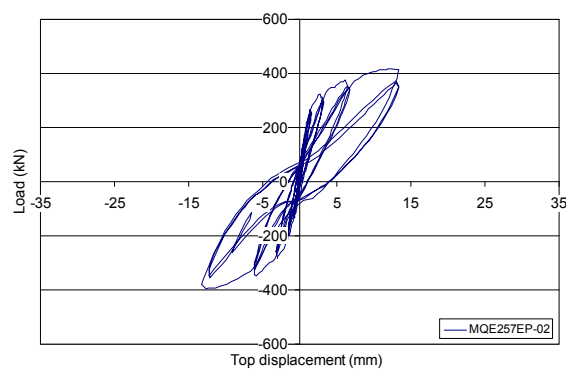

(e)

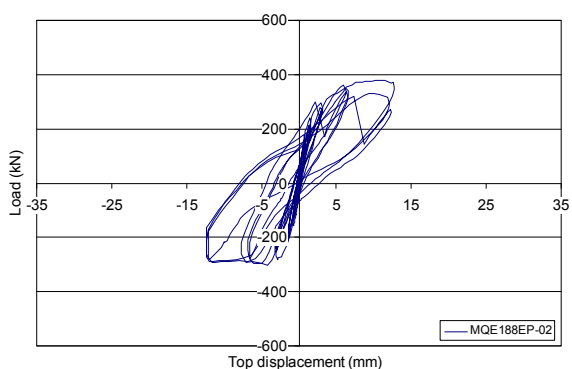

(b)

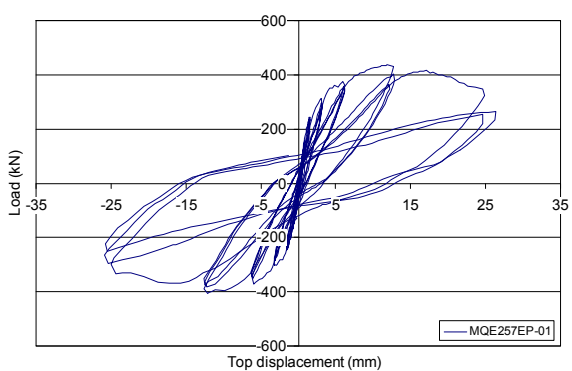

(d)

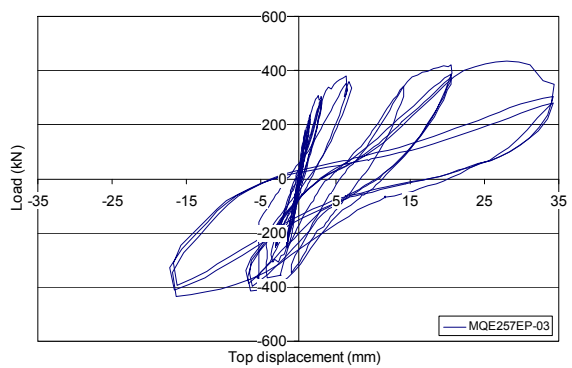

(f)

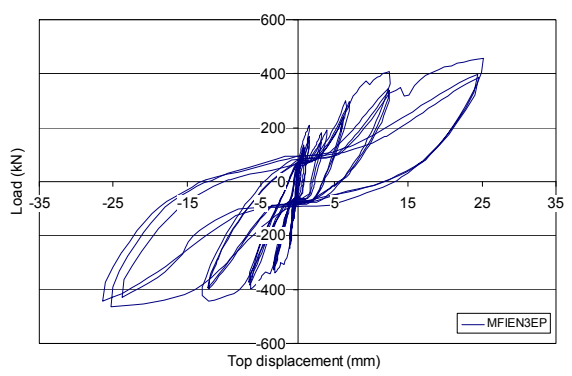

(g)

Fig. 4. Overall hysteretic responses of walls, (a) MQE188EP-01, (b) MQE188EP-02; (c) MQE188EP-03, (d) MQE257EP-01, (e) MQE257EP-02, (f) MQE257EP-03, and (g) MFIEN3EP 


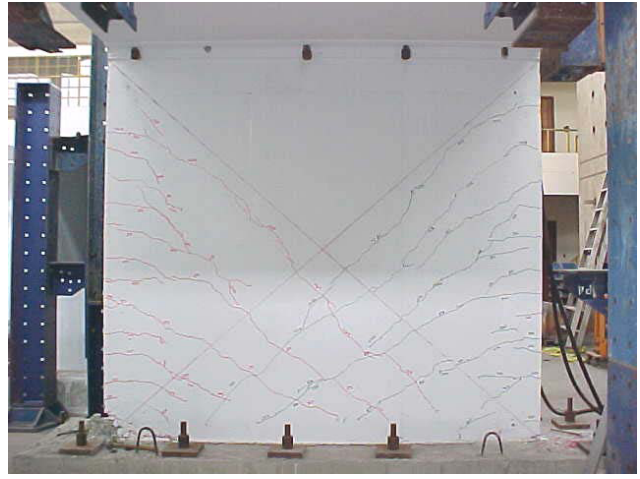

(a)

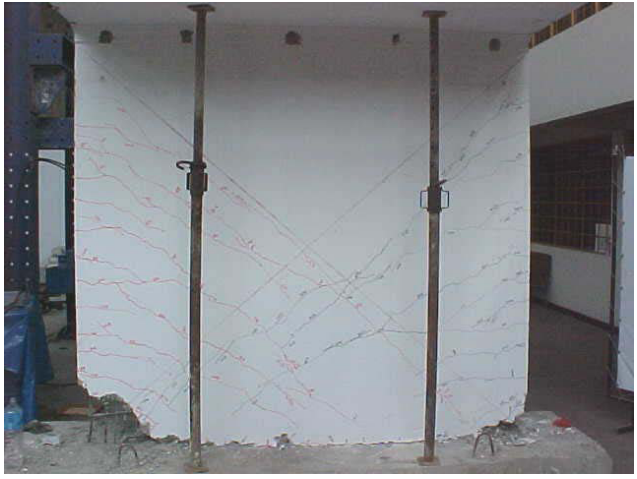

(b)

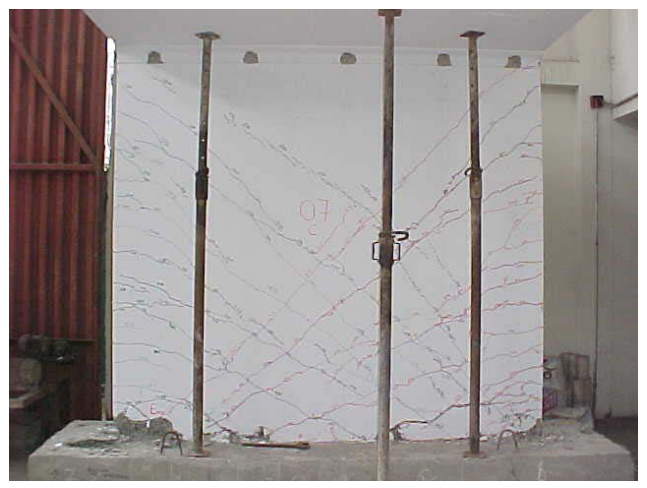

(c)

Fig. 5. Final state of walls a) MQE188EP-01, b) MQE257EP-02, and c) MFIEN3EP [12] 


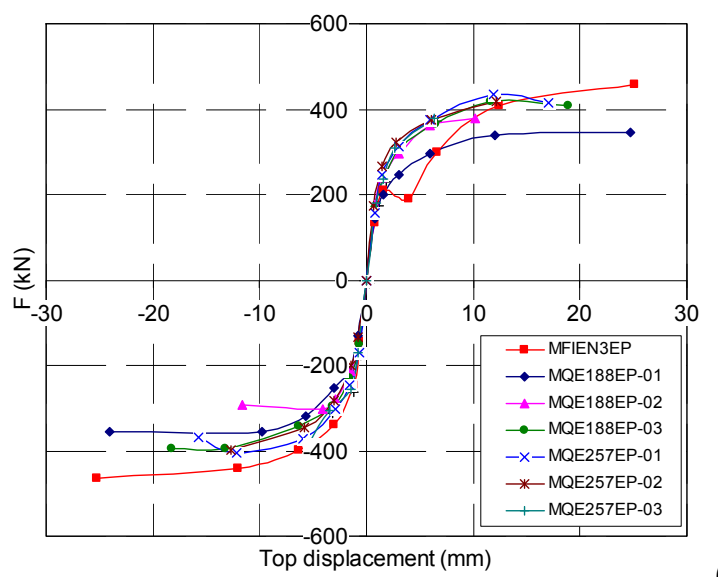

(a)

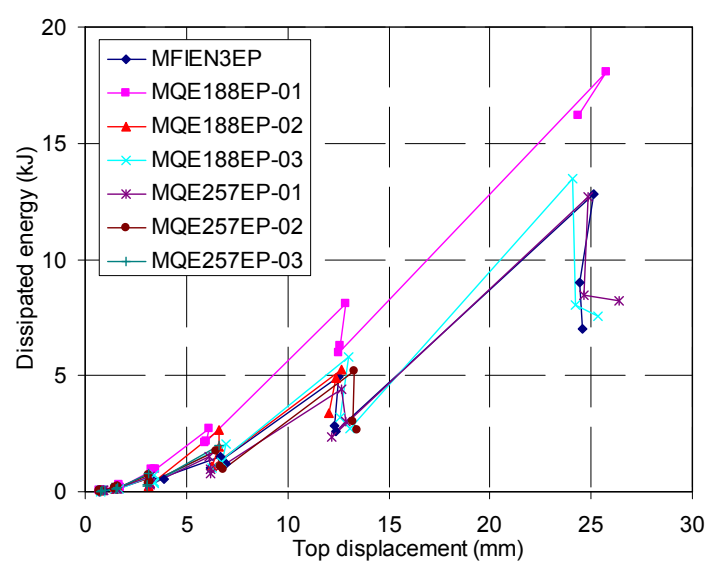

(c)

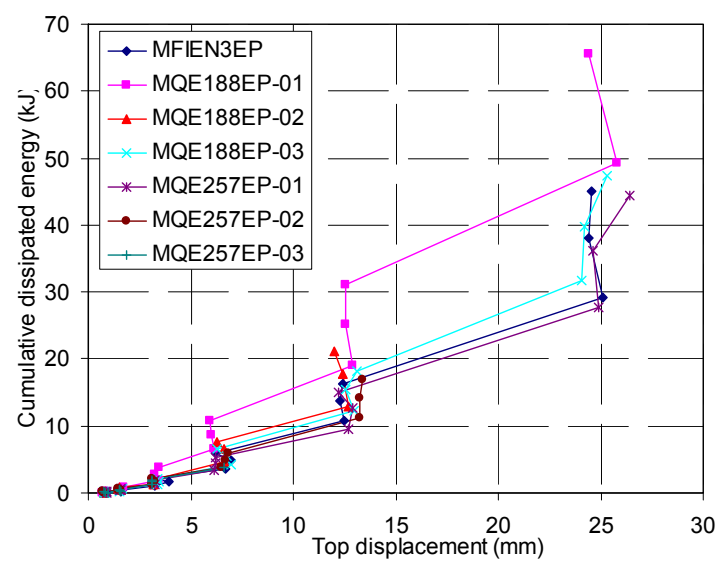

(d)

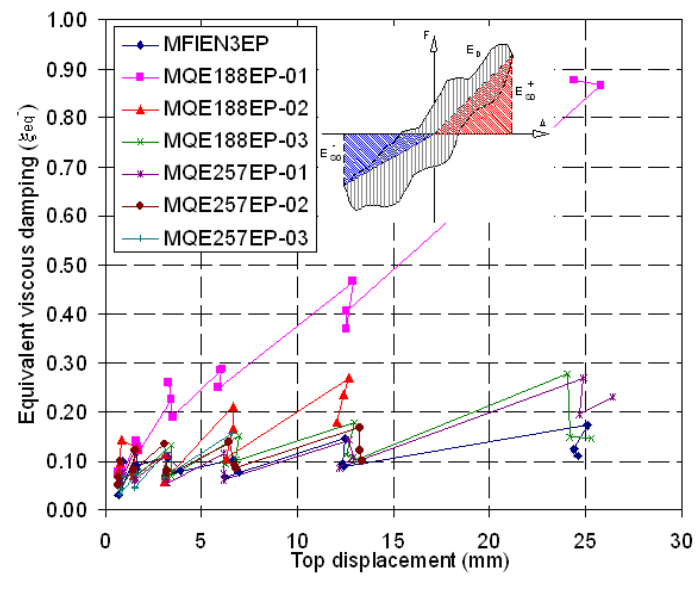

(e)

Fig. 6. Structural characteristics: (a) Skeleton curves, (b) lateral equivalent stiffness, (c) energy dissipated, (d) cumulative dissipated energy and (e) equivalent viscous damping with respect to displacement at the top of the walls 


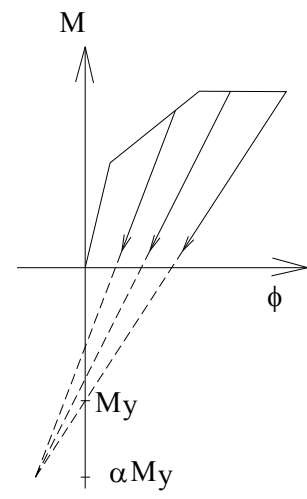

(a)

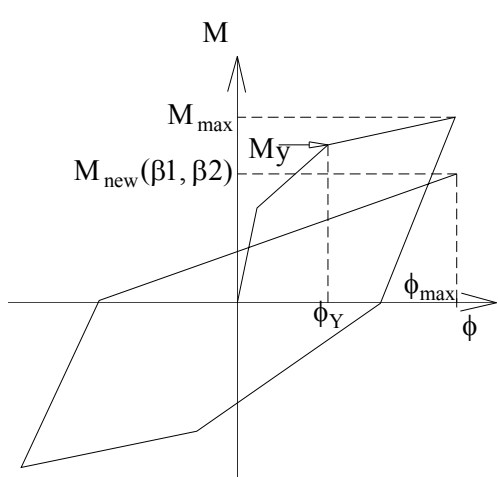

(b)

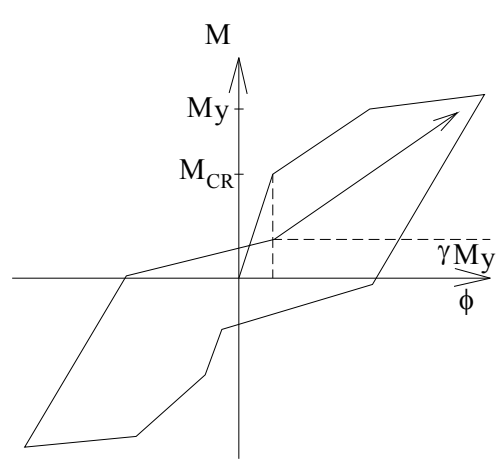

(c)

Fig. 7. Graphical representations of the influences of (a) $\alpha$, (b) $\beta 1, \beta 2$, and (c) $\gamma$ on the hysteretic curve 

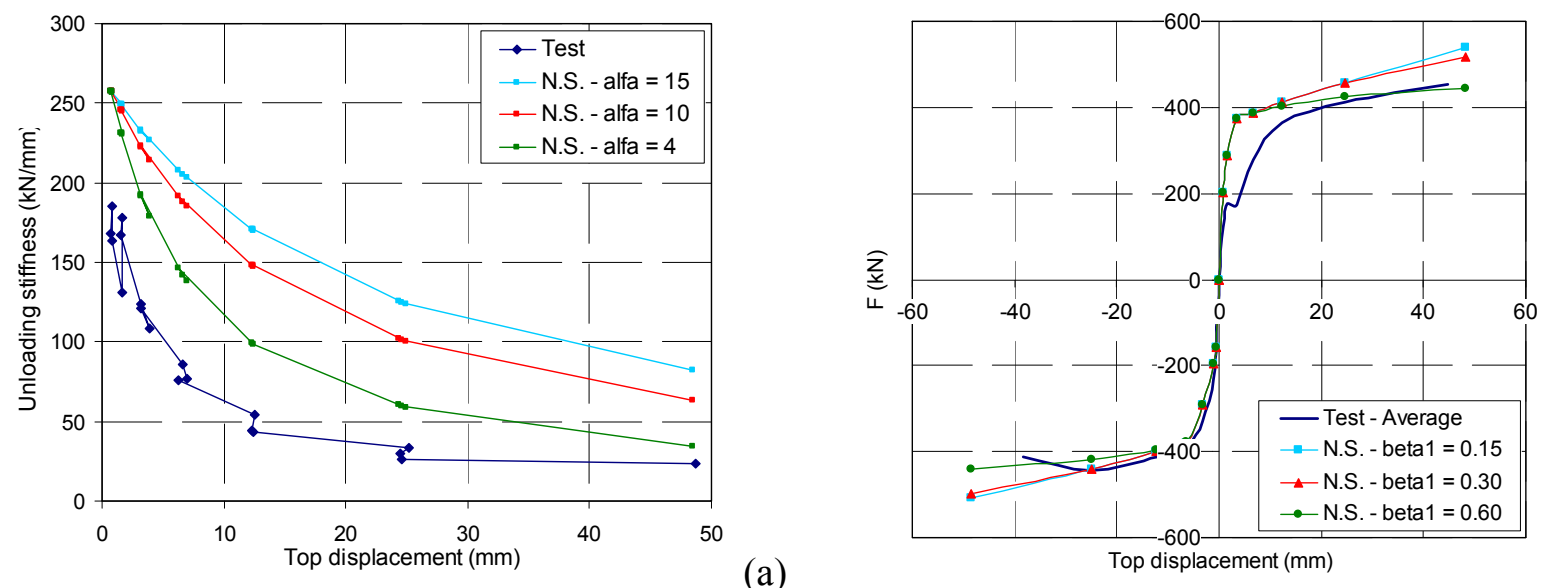

(b)

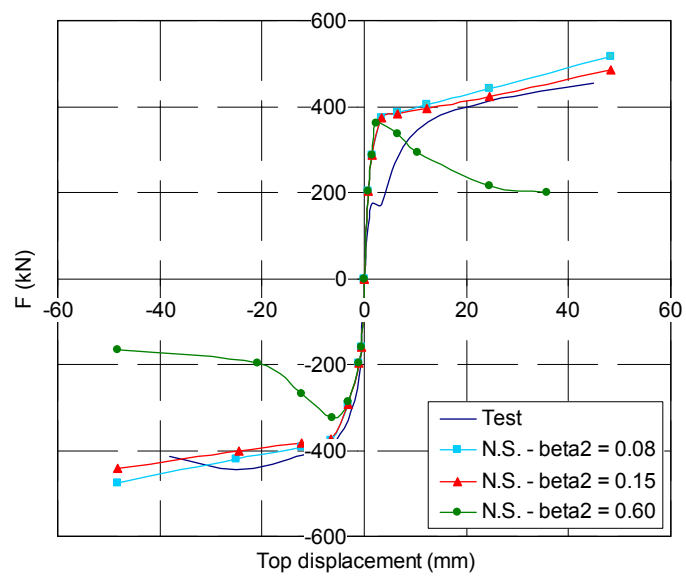

(c)

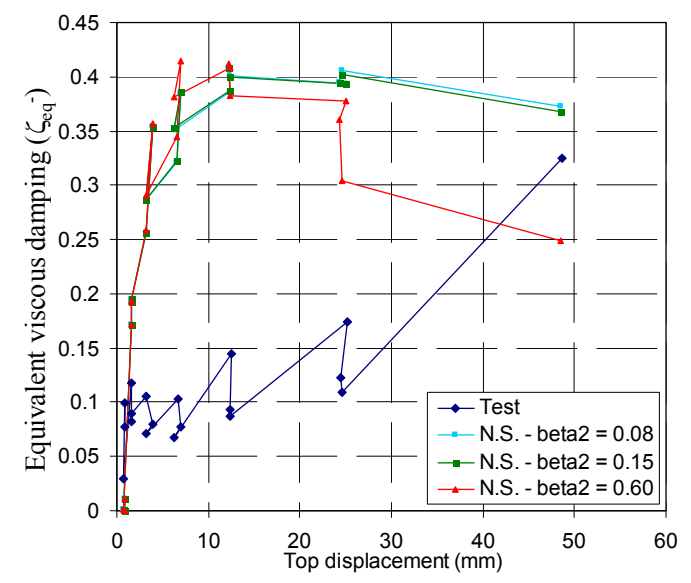

(d)

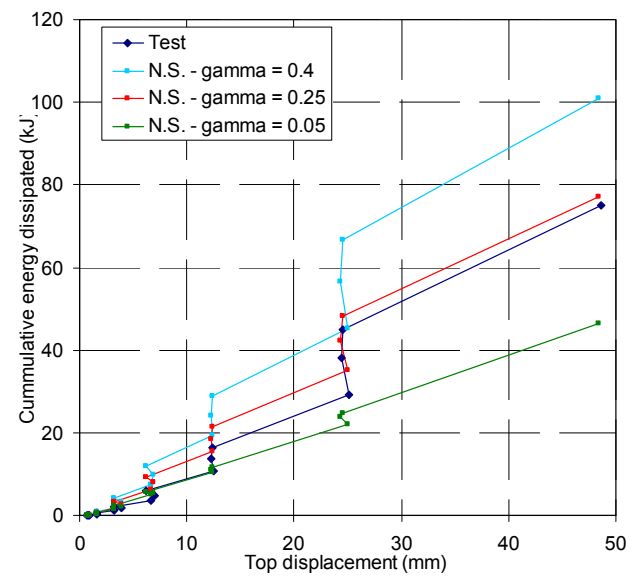

(e)

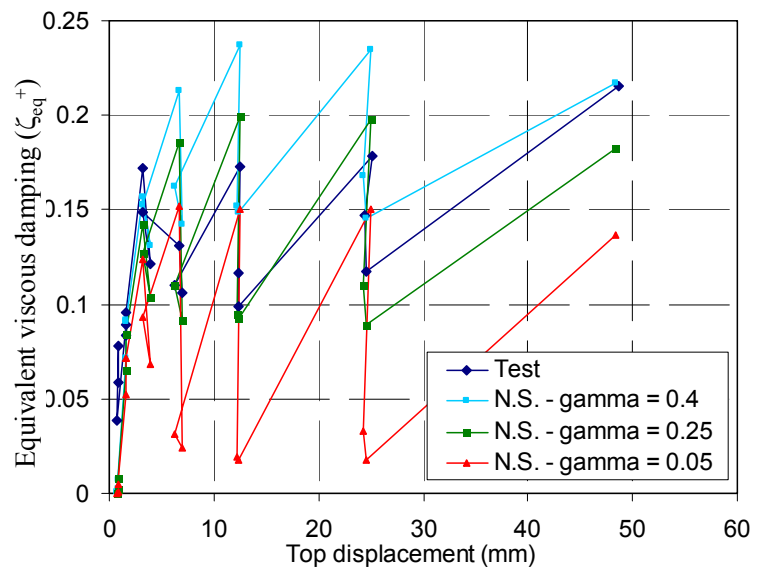

Fig. 8. Influence of parameters in structural characteristics: (a) $\alpha$ on unloading stiffness, (b)

$\beta 1$ on strength, (c) $\beta 2$ on strength, (d) $\beta 2$ on equivalent viscous damping, (e) $\gamma$ on energy dissipated and (f) $\gamma$ on equivalent viscous damping 


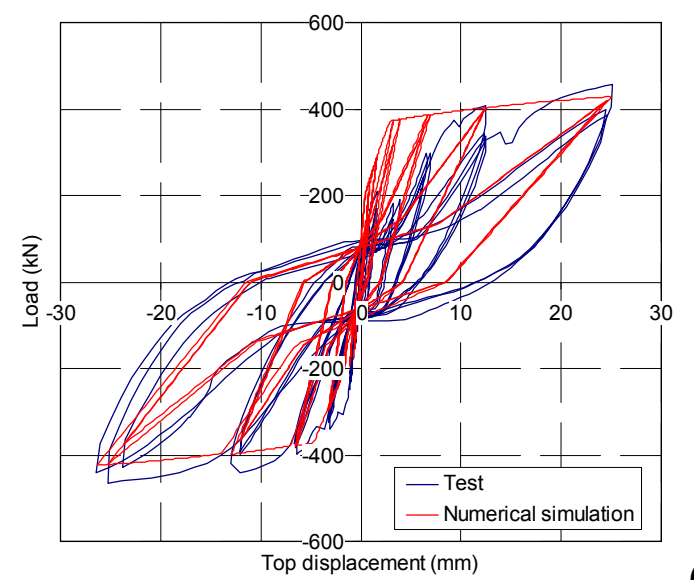

(a)

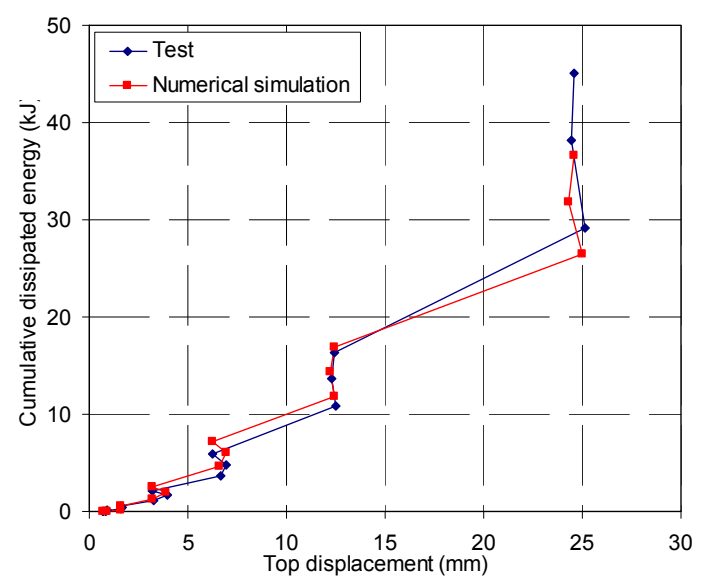

(c)

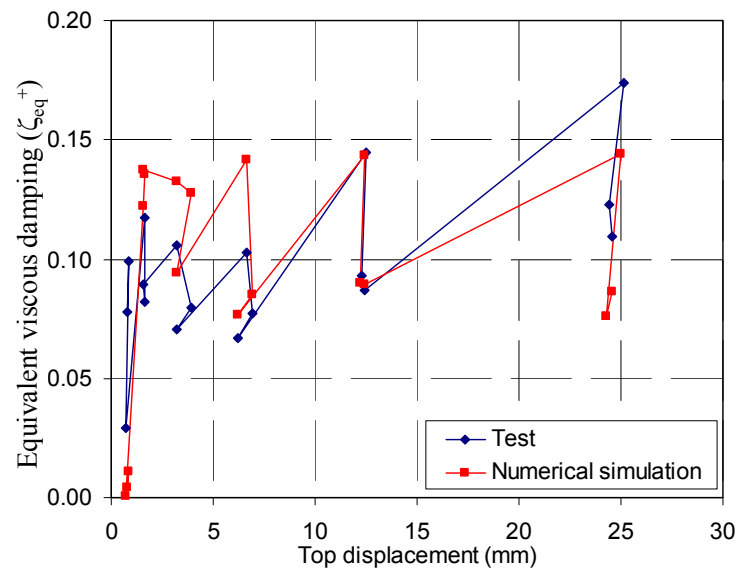

(e)

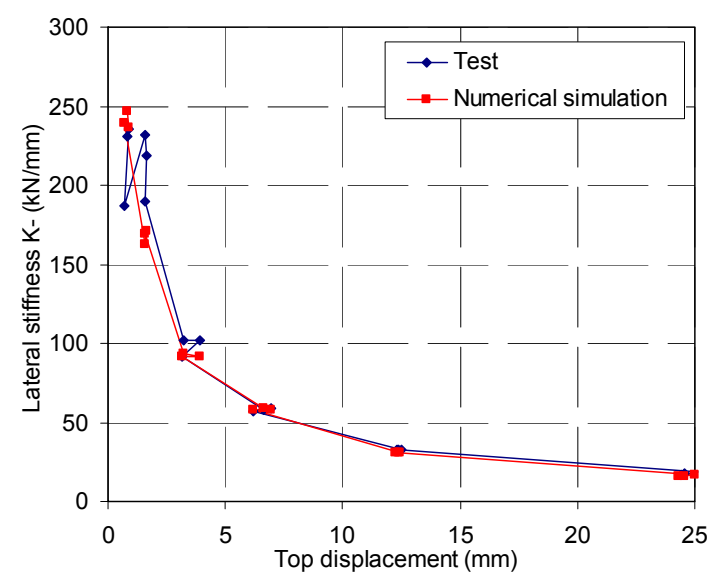

(b)

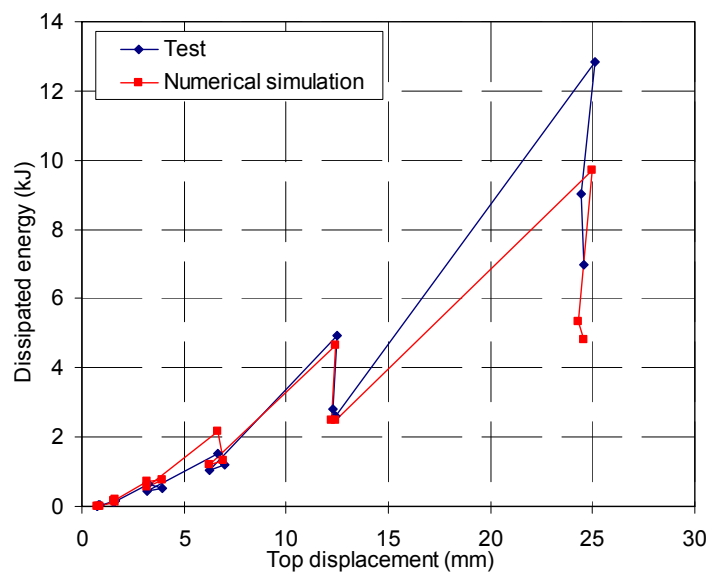

(d)

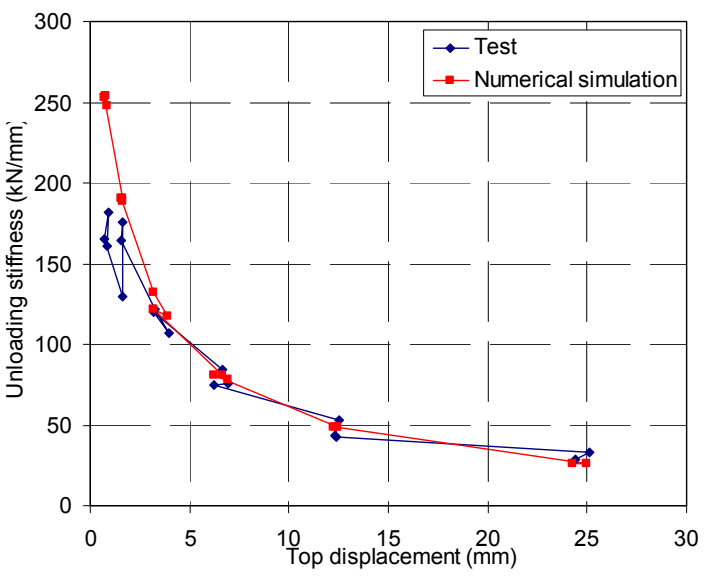

(f)

Fig. 9. Comparison of test results versus numerical simulation for the wall MFIEN3EP: a) hysteresis curves, (b) stiffness degradation, (c) cumulative energy dissipated, (d) dissipated energy, (e) equivalent viscous damping and (f) unloading stiffness 


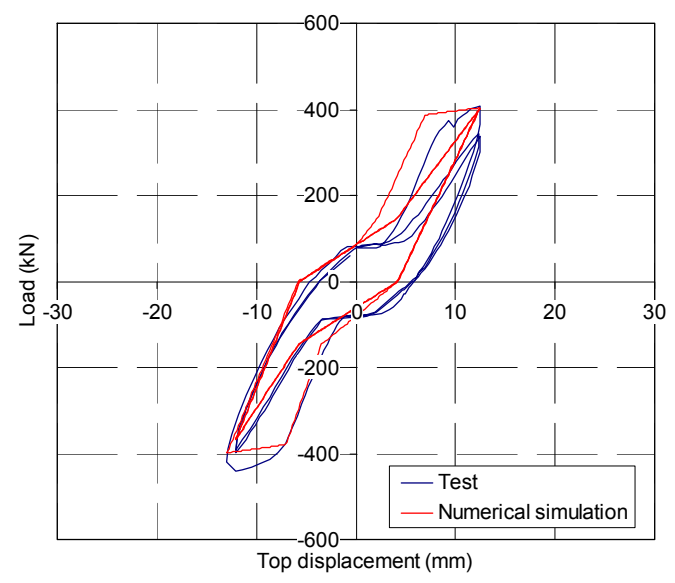

(a)

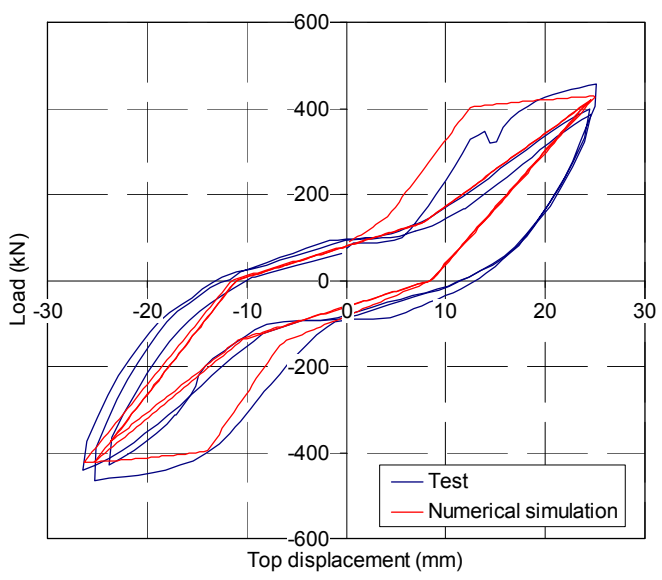

(b)

Fig. 10. Comparison of hysteretic curves for wall MFIEN3EP in a) phase 5 and b) phase 6 


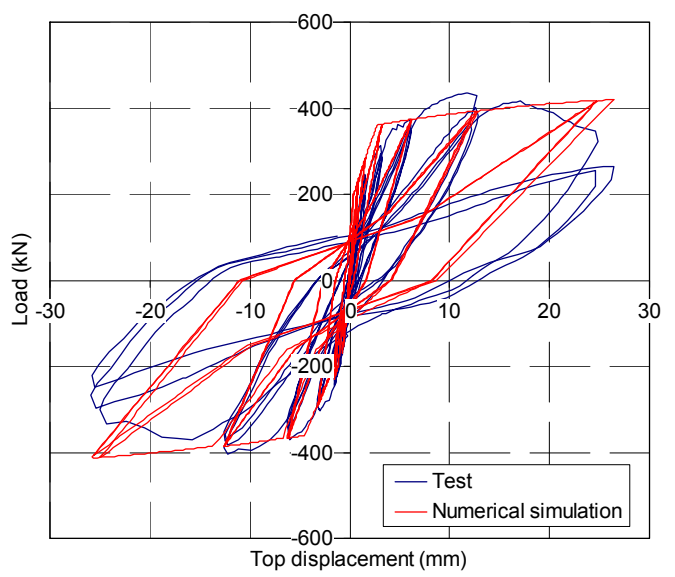

(a)

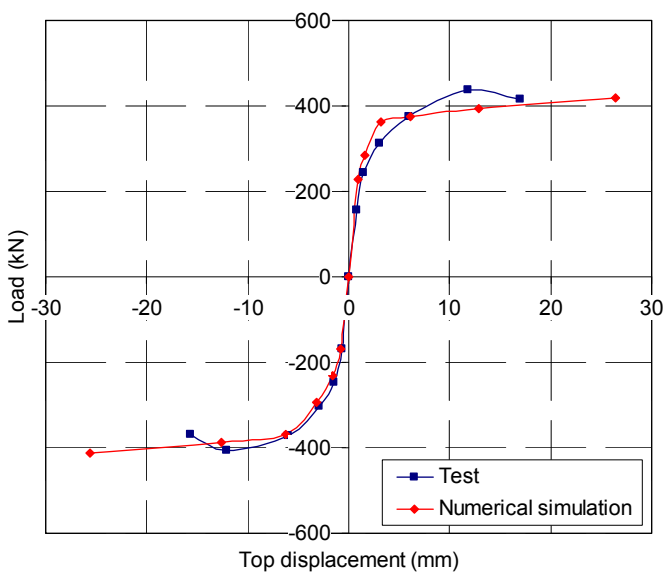

(b)

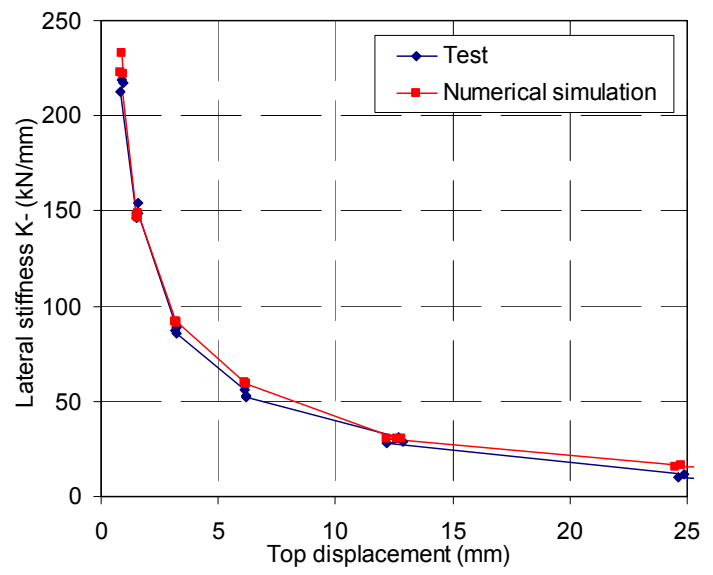

(c)

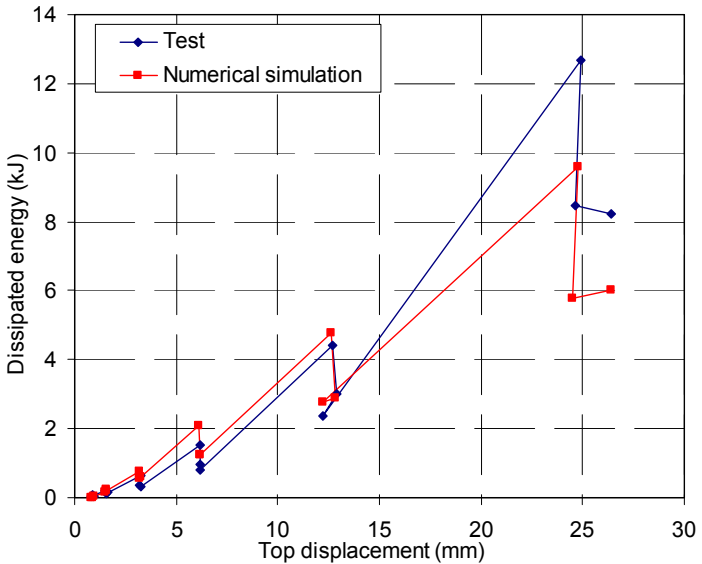

(d)

Fig. 11. Comparison of the results from the test and numerical simulation for MQE257EP-01 with respect to a) hysteretic curve, b) skeleton curve, c) lateral stiffness, d) dissipated energy, e) equivalent viscous damping, and f) unloading stiffness 

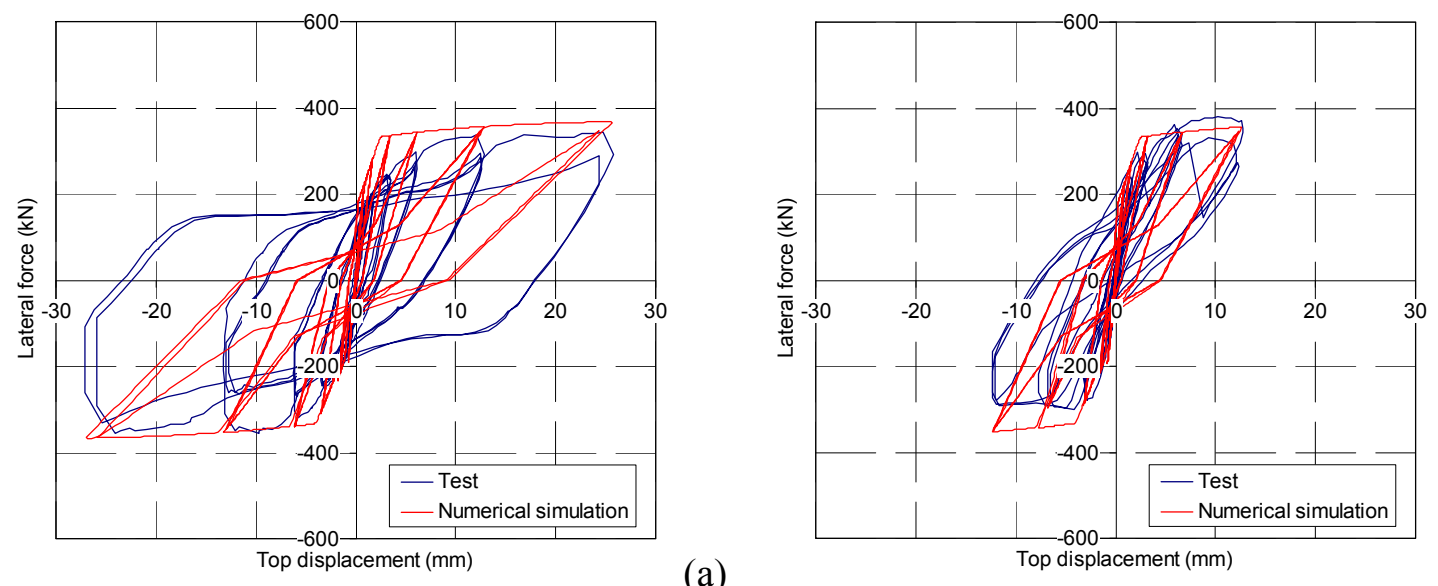

(b)
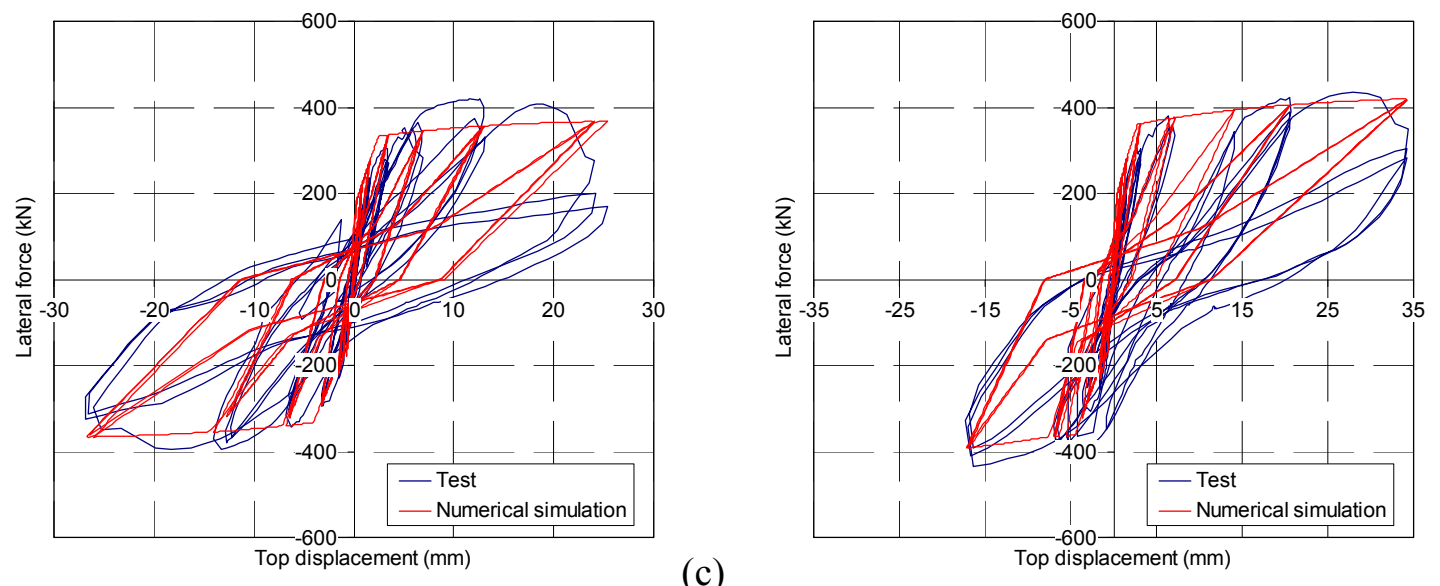

(c)

(d)

Fig. 12. Comparison of the hysteretic curves obtained from the numerical simulation and tests for the walls: a) MQE188EP-01, c) MQE188EP-02, c) MQE188EP-03, and d) MQE257EP-03 